\title{
Biological response of adrenal carcinoma and melanoma cells to mitotane treatment
}

\author{
EWELINA STELCER ${ }^{1,2}$, HANNA KOMAROWSKA ${ }^{3}$, KAROL JOPEK $^{1}$, AGNIESZKA ŻOK $^{4}$, DARIUSZ IŻYCKI $^{5}$, \\ AGNIESZKA MALIŃSKA ${ }^{1}$, BEATA SZCZEPANIAK ${ }^{1}$, ZHANAT KOMEKBAI $^{6}$, MAREK KARCZEWSKI ${ }^{7}$, \\ TOMASZ WIERZBICKI $^{8}$, WIKTORIA MARIA SUCHORSKA ${ }^{2}$, MAREK RUCHAŁA $^{3}$ and MARCIN RUCIŃSKI ${ }^{1}$ \\ ${ }^{1}$ Department of Histology and Embryology, Poznan University of Medical Sciences, 61-001 Poznan; \\ ${ }^{2}$ Radiobiology Laboratory, Greater Poland Cancer Centre, 61-866 Poznan; ${ }^{3}$ Department of Endocrinology, \\ Metabolism and Internal Medicine, Poznan University of Medical Sciences, 60-355 Poznan; \\ ${ }^{4}$ Division of Philosophy of Medicine and Bioethics, Department of Social Sciences and Humanities, \\ Poznan University of Medical Sciences, 60-806 Poznan; ${ }^{5}$ Department of Cancer Immunology, Poznan University of \\ Medical Sciences, 61-866 Poznan, Poland; ${ }^{6}$ Department of Histology, West Kazakhstan Marat Ospanov Medical University, \\ Aktobe 030019, Kazakhstan; Departments of ${ }^{7}$ General and Transplantation Surgery, and \\ ${ }^{8}$ General, Endocrinological and Gastroenterological Surgery, Poznan University of Medical Sciences, 60-355 Poznan, Poland
}

Received July 31, 2021; Accepted December 2, 2021

DOI: $10.3892 / \mathrm{ol} .2022 .13240$

\begin{abstract}
A previous case report described an adrenal incidentaloma initially misdiagnosed as adrenocortical carcinoma (ACC), which was treated with mitotane. The final diagnosis was metastatic melanoma of unknown primary origin. However, the patient developed rapid disease progression after mitotane withdrawal, suggesting a protective role for mitotane in a non-adrenal-derived tumor. The aim of the present study was to determine the biological response of primary melanoma cells obtained from that patient, and that of other established melanoma and ACC cell lines, to mitotane treatment using a proliferation assay, flow cytometry, quantitative PCR and microarrays. Although mitotane inhibited the proliferation of both ACC and melanoma cells, its role in melanoma treatment appears to be limited. Flow cytometry analysis and transcriptomic studies indicated that the ACC cell line was highly responsive to mitotane treatment, while the primary melanoma cells showed a moderate response in vitro. Mitotane modified the activity of several key biological processes, including 'mitotic nuclear division', 'DNA repair', 'angiogenesis' and 'negative regulation of ERK1 and ERK2 cascade'. Mitotane administration led to elevated levels of DNA double-strand breaks, necrosis and apoptosis. The present study provides a comprehensive insight into the biological response of mitotane-treated cells at the molecular
\end{abstract}

Correspondence to: Dr Ewelina Stelcer, Department of Histology and Embryology, Poznan University of Medical Sciences, 6 Swiecickiego Street, 61-001 Poznan, Poland

E-mail: ewelina.stelcer@ump.edu.pl

Key words: adrenocortical carcinoma, melanoma metastasis, mitotane level. Notably, the present findings offer new knowledge on the effects of mitotane on ACC and melanoma cells.

\section{Introduction}

Adrenocortical tumors are relatively common, with a prevalence of $3-10 \%$ in the general population (1). These tumors can be categorized into adrenocortical adenoma and adrenocortical carcinoma (ACC), which is rare, with a reported incidence of only 2 cases per 1,000,000 individuals per year (2). ACC is most common in women (55-60\% of cases) in their 4th or 5th decade of life. However, ACC can affect patients at any age, including children (3). Geographical factors also appear to serve a role, with a higher incidence in certain regions of the world, such as in southern and southwestern Brazil (4). The 5-year survival rate of individuals with adrenocortical carcinoma is $50 \%$ (5).

The main drug currently approved for the treatment of ACC is mitotane (2,4'-dichlorodiphenyl)dichloroethane, 1-(2-chlorophenyl)-1-(4-chlorophenyl)-2,2-dichloroethane). The recommended therapeutic window for plasma mitotane levels is $14-20 \mathrm{mg} / 1(\sim 50 \mu \mathrm{M})(6,7)$. However, the efficacy of this drug is limited due to its low pharmacokinetic properties and dose-limiting toxicity (8-10). Mitotane is an insecticidederivative lipophilic drug that accumulates in lipoproteins, and dyslipidemia has been observed in certain mitotane-treated patients with ACC (11). Mitotane raises the concentration of cortisol-binding globulin hormone, steroid-binding globulin and thyroxine-binding globulin, and it may also impair pituitary gland function by reducing the secretion of thyroid stimulating hormone, thus leading to hypothyroidism (12). The action of mitotane on adrenal steroidogenesis has been associated with the inhibition of a number of mitochondrial cytochrome P450-dependent enzymes, including cholesterol side-chain cleavage, $11 \beta$-hydroxylase and $18 \beta$-hydroxylase, as 
well as P450-independent enzymes, such as $3 \beta$-hydroxystero id-dehydrogenase (13). Mitotane contributes to the induction of respiratory chain impairment, leading to decreased aspartate and increased glutamate content (14). This drug has also been shown to inhibit the expression of the voltage-dependent anion channel, a protein anchored to the outer mitochondrial membrane $(15,16)$.

A recent report described an unusual case of a patient admitted to the Department of Endocrinology, Metabolism and Internal Medicine at Poznan University of Medical Sciences (Poznan, Poland) in September 2017 (17). The patient was initially diagnosed with ACC and treated with mitotane therapy. However, due to the unusual course of the disease, an experienced pathologist re-analyzed all the tissue samples, and noticed that all had the same immunophenotype and morphology. As a result, the initial diagnosis of ACC was changed to metastatic melanoma of unknown primary origin. The most notable aspect of that case was the rapid disease progression after mitotane withdrawal, which suggested that mitotane may play a protective and stabilizing role in non-adrenal-derived tumors (17).

Based on the aforementioned case report, the present study aimed to compare the biological response of ACC and melanoma cells after mitotane treatment. The cell proliferation rate was determined, and cytometric analysis of key processes involved in the response to cytostatic treatment [including mitochondrial membrane potential, DNA double-strand breaks (DSBs), necrosis, apoptosis and cell cycle] was performed, alongside gene expression profiling.

\section{Materials and methods}

Cell culture of metastatic melanoma in the left adrenal gland of unknown primary origin. To establish a primary culture of metastatic melanoma, a sample from a specimen for which several immunohistochemical analyses targeting melanoma markers were previously performed, as described in detail in a previous publication (17), was used.

Adrenal metastases of melanoma tumor samples obtained during surgery, were cut into several small pieces, and the fragments were further dissociated enzymatically in $25 \mathrm{ml}$ DMEM F12 (Thermo Fisher Scientific, Inc.) containing $0.1 \%$ type I collagenase (cat. no. 17018029; Thermo Fisher Scientific, Inc.) for $45 \mathrm{~min}$ at $37^{\circ} \mathrm{C}$ in a water bath with intermittent mixing. After digestion, the mixture was filtered through a $70-\mu \mathrm{M}$ sieve. Next, the tissue was centrifuged at $4^{\circ} \mathrm{C}$ and $300 \mathrm{x}$ for $7 \mathrm{~min}$. The cell pellet was resuspended in the DMEM F12 containing $0.5 \%$ penicillin-streptomycin (cat. no. P4333; Merck KGaA) and $10 \%$ fetal bovine serum (FBS; HyClone; Cytiva). The primary cell line was cultured at $37^{\circ} \mathrm{C}$ in the presence of $5 \% \mathrm{CO}_{2}$ in a humidified atmosphere until reaching $70 \%$ confluence. The cells exhibited key melanoma markers $(18,19)$ : CSPG4, FN1, TYRP1, MCAM and SPP1 (selected by transcriptomic studies using microarrays) (Fig. S1).

Cell culture of commercially available cells lines. The HAC15 cell line (cat. no. CRL-3301TM; American Type Culture Collection) was cultured in a defined medium consisting of DMEM/F12 without phenol red (Thermo Fisher Scientific, Inc.), 10\% Cosmic Calf Serum (HyClone; Cytiva),
$1 \%$ insulin-transferrin-selenium + Premix (cat. no. 25-800-CR; Corning, Inc.) and $1 \%$ penicillin-streptomycin. Importantly, the HAC15 cell line was authenticated using STR analysis by the supplier.

The metastatic human melanoma WM266-4 cell line (Rockland Immunochemicals, Inc.) was cultured in medium consisting of high-glucose DMEM (Thermo Fisher Scientific, Inc.), $10 \%$ FBS (HyClone; Cytiva) and 1\% P/S (MilliporeSigma). The wild-type TTP53 status of both commercial cell lines was previously confirmed $(20,21)$.

HAC15, WM266-4 and primary melanoma cell treatment. These cells $\left(2 \times 10^{6}\right)$ were incubated with mitotane $(50 \mu \mathrm{M})$ for $24 \mathrm{~h}\left(37^{\circ} \mathrm{C}\right.$ in the presence of $5 \% \mathrm{CO}_{2}$ in a humidified atmosphere) and then subjected to further analyses. Based on the opinion of clinicians (HK, Department of Endocrinology, Metabolism and Internal Medicine, Poznan University of Medical Sciences, Poznan, Poland; MK, General and Transplantation Surgery, Poznan University of Medical Sciences, Poznan, Poland; TW, General, Endocrinological and Gastroenterological Surgery, Poznan University of Medical Sciences, Poznan, Poland; and MareR, Department of Endocrinology, Metabolism and Internal Medicine, Poznan University of Medical Sciences, Poznan, Poland), a time point (24 h) that is both clinically and biologically important was selected for this study. Specifically, at this time point, the greatest changes in cell proliferation were observed, which should reflect dynamic changes in gene expression $(22,23)$. Therefore, material collected after $24 \mathrm{~h}$ of mitotane treatment was selected for further microarray analysis.

Real-time cell analyzer (RTCA)-based cell proliferation assay. To verify the effect of a wide range of concentrations of mitotane $(10,20,40,60$ and $80 \mu \mathrm{M})$ on the proliferation rate of the evaluated cells ( $n=6 /$ group; 1,000 cells per well), an RTCA electrical impedance-based cell proliferation assay (xCELLigence RTCA; Roche Diagnostics GmbH) was used. The RTCA system detects fluctuations in electrical impedance on the integrated sensory electrodes, which are located at the bottom of the 16-hole slide plates of the chamber (E-Plate 16), which are covered by dividing cells. Electrical impedance is determined at 15-min intervals during the culture period ( $40 \mathrm{~h}$ after mitotane delivery). The main RTCA parameter is the cell index $(\mathrm{CI})$, which refers to the relative change in electrical impedance depending on the rate of proliferation or apoptosis of the cultured cells. The CI values were normalized to obtained a normalized cell index (NCI), which was calculated for each time point according to the following formula: $\mathrm{NCI}=\mathrm{CI}$ time point/CI mitotane delivery.

The characteristic parameters of cell proliferation, including doubling time and dose-dependent rate of decrease, and the half-maximal response to mitotane, were calculated. Doubling time is the time (in $\mathrm{h}$ ) required to double NCI (positive values) or to reduce it by half (negative values) based on the curve-fit from the first $24 \mathrm{~h}$ after mitotane administration. All calculations, such as $\mathrm{R}^{2}$ (regression line fit), rate of decrease and slope were performed using RTCA software v.1.2.1.1002 according to the manufacturer's protocol (Roche Diagnostics $\mathrm{GmbH}$ ) and then visualized in the ggplot2 package of the $\mathrm{R}$ programming language (https://cran.r-project. 
org/web/packages/ggplot2/index.html). The effect of mitotane on HAC15, WM266-4 and primary melanoma cell proliferation was evaluated in two independent experiments.

Flow cytometry analysis of phosphorylated at serine 139 version of histone $H 2 A X(\gamma H 2 A X)$ and cleaved poly (ADP-ribose) polymerase 1 (PARP-1). Cells (HAC15, WM266-4 and primary melanoma) were stained for $\gamma \mathrm{H} 2 \mathrm{AX}$ with Alexa Fluor $^{\circledR} 647$ Mouse anti-H2AX (cat. no. 560447; BD Biosciences) and cleaved PARP-1 with PE Mouse anti-Cleaved PARP (Asp214) (cat. no. 562253; BD Biosciences) antibodies according to the manufacturer's instructions. Briefly, $1 \times 10^{6}$ untreated and mitotane-treated cells were fixed and permeabilized with Cytofix/Cytoperm ${ }^{\mathrm{TM}}$ Fixation/Permeabilization Solution (BD Biosciences) for $30 \mathrm{~min}$ at room temperature. Additional permeabilization and fixation as recommended by the manufacturer's protocol were then performed. The fixed cells were once washed with $1 \mathrm{ml}$ Perm/Wash Buffer (BD Biosciences) at room temperature for $5 \mathrm{~min}$ and stained with an appropriate antibody (5 $\mu \mathrm{l} /$ assay in $20 \mu \mathrm{l} \mathrm{BD} \mathrm{Perm} /$ Wash Buffer) for $20 \mathrm{~min}$ at room temperature. Cells were then resuspended in $1 \mathrm{ml}$ PBS and analyzed with a flow cytometer (CytoFlex; Beckman Coulter, Inc.). Fluorescence intensity in arbitrary units was represented in histograms, and the mean fluorescence intensity was calculated. Data were analyzed using FlowJo software v10 (FlowJo LLC). Untreated cells served as a control. The mean fluorescence intensity from three experiments was normalized to 1 . Treated cells were compared with the control.

Flow cytometry analysis of necrosis and the cell cycle. Cell cycle analysis was performed using a propidium iodide (cat. no. P1304MP; Thermo Fisher Scientific, Inc.). Briefly, treated cells $\left(1 \times 10^{6}\right)$ were fixed in cold $\left(-20^{\circ} \mathrm{C}\right) 70 \%$ ethanol by adding this dropwise to the cell suspension while vortexing. Next, the cells were rinsed with PBS and incubated with a mixture of $10 \mu \mathrm{l}$ propidium iodide $(1 \mathrm{mg} / \mathrm{ml}), 188 \mu \mathrm{l}$ PBS and $2 \mu \mathrm{l}$ RNAse $(10 \mathrm{mg} / \mathrm{ml}$; Thermo Fisher Scientific, Inc.). Cells were incubated at $37^{\circ} \mathrm{C}$ for $30 \mathrm{~min}$, and then rinsed and resuspended in $200 \mu 1 \mathrm{PBS}$. The fluorescence intensity of the sample was determined with a blue laser $(488 \mathrm{~nm})$ and detection filters $610 / 20 \mathrm{~nm}$ bandpass for PI. The procedure to determine necrosis was similar to that used for cell cycle analysis, with the following exceptions: i) RNAse was not added to the unfixed cells and ii) incubation with propidium iodide was performed at $4^{\circ} \mathrm{C}$ for $30 \mathrm{~min}$.

Flow cytometry analysis of mitochondrial membrane potential. Mitochondrial membrane potential analysis was performed using JC-1 solution (cat. no. T3168; Thermo Fisher Scientific, Inc.) at a final concentration of $100 \mu \mathrm{M}$. The resuspended cells $\left(1 \times 10^{6}\right)$ were stained for $20 \mathrm{~min}$ at $37^{\circ} \mathrm{C}$. At low concentrations (low mitochondrial membrane potential), JC-1 is predominantly a monomer that yields green fluorescence with emission of $530 \mathrm{~nm}$. In turn, at high concentrations (high mitochondrial membrane potential), the dye aggregates yielding a red to orange colored emission $(590 \mathrm{~nm})$. This correlates to the FL-2 and FL-1 channels (24). The results were depicted as mean fluorescence that was subsequently normalized (the value of the control was set as 1).
Reverse transcription-quantitative PCR (RT-qPCR). Total RNA was extracted from cells with Direct-zol ${ }^{\mathrm{TM}}$ RNA MiniPrep columns (Zymo Research Corp.). Total RNA (1 $\mu \mathrm{g}$ per $20 \mu \mathrm{l}$ reaction volume) was reverse transcribed using an iScript cDNA Synthesis Kit (Bio-Rad Laboratories, Inc.). qPCR (Initial denaturation at $95^{\circ} \mathrm{C}$ for $5 \mathrm{~min} ; 44$ cycles of denaturation at $95^{\circ} \mathrm{C}$ for $10 \mathrm{sec}$, amplification at $60^{\circ} \mathrm{C}$ for $30 \mathrm{sec}$ and elongation at $72^{\circ} \mathrm{C}$ for $1 \mathrm{sec}$ ) was performed using the LightCycler ${ }^{\circledR} 480$ Probes Master (Roche Diagnostics) and the appropriate probe for each primer (5'-3'): TTP53 forward, 5'-CTTTCCACGACGGTGACA-3' and reverse, 5'-TCCTCC ATGGCAGTGACC-3'; BRCA2 forward, 5'-CCTGATGCC TGTACACCTCTT-3' and reverse, 5'-GCAGGCCGAGTA CTGTTAGC-3'; RAD51 forward, 5'-ATCACTAATCAG GTGGTAGC-3' and reverse, 5'-CCCCTCTTCCTTTCCTCA GA-3'; XRCC4 forward, 5'-TGGTGAACTGAGAAAAGC ATTG-3' and reverse, 5'-TGAAGGAACCAAGTCTGAATG A-3'; PRKDC forward, 5'-AGAGGCTGGGAGCATCAC T-3' and reverse, 5'-CACCAAGGCTTCAAACACAA-3'; BAX forward, 5'-ATGTTTTCTGACGGCAACTTC-3' and reverse, 5'-ATCAGTTCCGGCACCTTG-3'; BCL-2 forward, 5'-GCACCTGCACACCTGGAAT-3' and reverse, 5'-AGC CAGGAGAAATCAAACAGAG-3'; CDK2 forward, 5'-TGC TGGGAGAAATGGAAAAT-3' and reverse, 5'-CAGGAC TGCTGTGGGACATA-3'; and CDK4 forward, 5'-AACCTC TGATTGACAGCTACAGTG-3' and reverse, 5'-GGGTGG GATAGTTGAACACG-3'.

cDNA samples were analyzed for the following genes of interest: BAX, BCL-2, CDK2, CDK4, TTP53, RAD51 recombinase (RAD51), BRCA2 DNA repair associated (BRCA2), $\mathrm{X}$-ray repair cross complementing 4 (XRCC4) and protein kinase DNA-activated catalytic subunit (PRKDC), and for the reference gene GAPDH (cat. no. 05-190-541-001; Roche Diagnostics). The expression level for each target gene was calculated with the $2^{-\Delta \Delta C q}$ method (25). The reaction was performed in triplicate for each gene of interest. qPCR analysis was performed using a LightCycler ${ }^{\circledR} 96$ (Roche Diagnostics).

Microarray expression analysis. Microarray analysis was conducted as previously described (26-28). The isolated RNA (50-300 $\mathrm{ng} / \mu \mathrm{l}$ and not degraded) from melanoma and ACC cells was pooled into two samples per group, and the following groups were established: i) Untreated primary melanoma cell line; ii) mitotane-treated primary melanoma cell line; iii) untreated WM266-4 cell line; iv) mitotane-treated WM266-4 cell line; v) untreated HAC15 cell line; and vi) mitotane-treated $\mathrm{HAC} 15$ cell line.

Cells were treated with mitotane (final concentration, $50 \mu \mathrm{M})$ for $24 \mathrm{~h}$. Transcription in vitro, biotin labelling and cDNA fragmentation for further hybridization were performed with an Affymetrix GeneChip IVT Express Kit (Affymetrix; Thermo Fisher Scientific, Inc.) according to the manufacturer's instructions. The biotin-labelled fragments were hybridized with Affymetrix Gene Chip Human Genome U219 microarrays (Affymetrix; Thermo Fisher Scientific, Inc.) together with control cDNA and oligo B2 (Affymetrix; Thermo Fisher Scientific, Inc.). Hybridization was performed with an AccuBlock $^{\mathrm{TM}}$ Digital Dry Bath Hybridization Oven (Labnet International, Inc.) at $45^{\circ} \mathrm{C}$ for $16 \mathrm{~h}$. The microarrays were then washed $3 \mathrm{x}$ at room temp. for 5 ' and stained using Affymetrix 
GeneAtlas $^{\mathrm{TM}}$ Fluidics Station (Affymetrix; Thermo Fisher Scientific, Inc.) according to the manufacturer's protocol. The array strips were scanned using the imaging station of the GeneAtlas $^{\mathrm{TM}}$ system (Affymetrix; Thermo Fisher Scientific, Inc.). Preliminary analysis of the scanned chips was performed using GeneAtlas ${ }^{\mathrm{TM}}$ operating software (Affymetrix; Thermo Fisher Scientific, Inc.). The quality of the gene expression data was verified using the quality control criteria established by the software. The obtained CEL files were imported for downstream data analysis.

Microarray data analysis. All analyses were performed using the Bioconductor repository (https://bioconductor.org) with the relevant Bioconductor libraries as an extension of the statistical $\mathrm{R}$ programming language. The robust multiarray average normalization algorithm implemented in the 'Affy' Bioconductor library was used for normalization, background correction and calculation of the expression values of all examined genes (29). Biological annotation was obtained from the Bioconductor 'oligo' library, where an annotated data frame object was merged with a normalized data set to obtain a complete gene data table (30). Differential expression and statistical assessment were determined by applying the linear models for microarray data implemented in the 'limma' library (31). The selection criteria for significant changes in gene expression were based on absolute fold-change $>1.5$ and P-value with false discovery rate (FDR) correction (adjusted P-value) of 0.05. The result of this selection was presented as a volcano plot, showing the total number of upregulated and downregulated genes affected by mitotane. The top 10 upregulated and downregulated genes are presented in tables. The raw data files were also deposited in the Gene Expression Omnibus (GEO) repository at the National Center for Biotechnology Information (http://www.ncbi.nlm.nih.gov/geo/) under the GEO accession number GSE186870.

Assignment of differentially expressed genes to relevant Gene Ontology (GO) biological process (BP) terms. ENTREZ ids with fold-change values of differentially expressed genes (DEGs) were subjected to GO enrichment analysis using the Database for Annotation, Visualization and Integrated Discovery (DAVID) bioinformatics tool (32). Gene symbols of DEGs were uploaded to DAVID using the 'RDAVIDWebService' Bioconductor library (33), where DEGs were assigned to relevant GO terms, with subsequent selection of significantly enriched GO terms from the GO-BP direct database. The P-values of the selected GO terms were corrected using Benjamini-Hochberg procedure and were described as adjusted P-values (34). Relevant GO ontological groups with adjusted $\mathrm{P}<0.05$ and $\mathrm{N} /$ group $>5$ were visualized using a bubble plot. Detailed analysis of genes belonging to selected ontological groups, with their fold-change in expression, were presented as Circos plots using the 'GOplot' library (35).

Gene Set Enrichment Analysis (GSEA). GSEA was used to determine enrichment or depletion in gene expression between two biological groups within gene sets defined a priori (GO terms, pathways). The Kolmogorov-Smirnov statistical test was used to identify significantly enriched or depleted groups of genes (36). GSEA was conducted using the 'fgsea' library (37). The normalized fold-change values of all the genes in the microarray were $\log 2$-transformed. A predefined gene set from the GO-BP database (from the Molecular Signatures Database) was selected (38). Genes belonging to the selected set were ranked according to the difference in their expression level using the signal-to-noise ratio with a 10,000-fold permutation. The enrichment score was calculated for each selected gene set (39). These scores were normalized by their gene set size, and false-positives were corrected according to their FDR. Gene sets with an adjusted $\mathrm{P}<0.1$ were exported to Cytoscape v.3.7.2 to generate links between significantly enriched processes in the form of an enrichment map (40). Enriched terms were clustered and annotated using the AutoAnnotate v.1.3.2 Cytoscape plugin (41).

Identification of common mitotane-regulated genes in all experimental models. To identify common mitotane-regulated genes, DEGs in $\geq 1$ cell type were selected according to the aforementioned cut-off criteria, with the additional requirement that their fold-change values in other comparable groups were $>1.2$. This selection was carried out in the $\mathrm{R}$ statistical programming language. The expression values for the gene sets were transformed into z-scores, hierarchically clustered and visualized as heat maps using the pheatmap library (42). To determine the BPs regulated by mitotane, enrichment analysis was performed in the relevant ontological groups from the DAVID Bioinformatics Resources 6.8 tool with the GOTERM BP DIRECT database (https://david.ncifcrf.gov/tools.jsp). The procedure was performed as aforementioned. Relevant GO ontological groups with $\mathrm{n} /$ group $>3$ were visualized using a bubble plot. Interactions between individual genes and relevant GO terms were evaluated using Cytoscape v.3.7.2.

Clinically significant mitotane-affected genes regulated in the studied cells. Clinical descriptions with RNA sequencing data from 94 cases of ACC and 470 cases of skin cutaneous melanoma (SKCM) were downloaded from the public The Cancer Genome Atlas (TCGA) database using the FireBrowse server (http://gdac.broadinstitute.org/) (43). Next, the 'voom' algorithm from the 'limma' package was used for data normalization (31). Normalized data for common mitotane-regulated genes were extracted from the whole dataset. The obtained expression set was divided into two separate populations using median values as the cut-off point: Genes with expression above and below the median value were assigned to the high or low expression group, respectively. The hazard ratio (HR) value of the selected genes was calculated using Gene Expression Profiling Interactive Analysis 2 software (44). Genes with a statistically significant HR in ACC and SKCM underwent Kaplan-Meier survival analysis. Survival plots with log-rank P-value estimates were performed using the 'survival' R library (45) based on mortality events described in the clinical records.

Statistical analysis. The statistical analysis of microarray data was described in detail in previous subsections. All other data were statistically analyzed using GraphPad software v.5.0 (GraphPad Software, Inc.). All experiments were performed $\geq 3$ times. Results are presented as the mean \pm standard 
deviation. Differences between two groups were analyzed using an unpaired Student's t-test (treated cells were compared with the control). $\mathrm{P}<0.05$ was considered to indicate a statistically significant difference.

\section{Results}

Mitotane administered in a wide concentration range (10-80 $\mu \mathrm{M}$ ) inhibits the proliferation of primary melanoma cells, and of the WM226-4 melanoma and HAC15 ACC cell lines. The effect of a wide concentration range (10-80 $\mu \mathrm{M})$ of mitotane on the proliferation of primary melanoma, WM266-4 and HAC15 cells was determined by measuring the impedance of proliferating cells. As shown in Fig. 1A, mitotane inhibited primary melanoma, WM226-4 and HAC15 cell proliferation in a dose-dependent manner. The proliferation growth curve profile based on data collected from the first $24 \mathrm{~h}$ of culture after mitotane administration showed that mitotane increased the doubling time of primary melanoma cells at each of the evaluated doses (Fig. 1B). The doubling time increased as the dose increased, confirming the dose-specific effect of mitotane on the cultured cell population. HAC15 cells continued to proliferate at mitotane doses ranging from 10 to $80 \mu \mathrm{M}$, but required a much longer time to double the cell population compared with that of the controls. A linear regression model was then used to calculate the proliferation decrease rate. The proliferation profile of primary melanoma cells decreased the most with increasing doses (decrease rate, $97.9 \%$ ), followed by that of the melanoma cell line $(63.6 \%)$. A relatively small dose-dependent decrease in cell proliferation was observed in HAC15 cells (decrease rate, 16.1\%) (Fig. 1C).

Mitotane at a dose of $50 \mu \mathrm{M}$ leads to necrosis and cell cycle arrest in $G_{1}$ phase in the cell lines evaluated. First, it was confirmed that the mitochondrial membrane potential decreased in both HAC15 and WM266-4 cells after $24 \mathrm{~h}$ of incubation with mitotane $[\sim 0.64$ fold-change $(\mathrm{P}<0.05)$ and $\sim 0.76$ fold-change $(\mathrm{P}<0.001)$, respectively] (Fig. 2A). The slight changes observed in the primary melanoma cell line ( 0.94 fold-change) were not statistically significant.

DSBs were determined after mitotane administration (50 $\mu \mathrm{M}$ for $24 \mathrm{~h}$ ), and the results revealed that DSBs were most abundant in the treated HAC15 cell line (Fig. 2B). A $\sim 40 \%$ increase in DSBs was observed in treated HAC15 cells compared with that in control cells. In the WM266-4 cell line, a statistically significant increase of almost $10 \%$ in DSBs was also observed (mean fluorescence values). By contrast, primary melanoma cells did not show changes in the formation of DSBs after $24 \mathrm{~h}$ of exposure to chemotherapy.

Next, the expression of the key genes involved in DNA repair as well as DNA damage response (DDR) was analyzed, including TTP53, RAD51 [homologous recombination (HR)], BRCA2 (HR), X-ray repair cross complementing 4 (XRCC4) [non-homologous end joining (NHEJ)] and protein kinase DNA-activated catalytic subunit (PRKDC) (NHEJ). However, no significant changes in TTP53 expression in any of the cells evaluated were observed. Notably, after mitotane treatment, the expression of the RAD51 gene was significantly higher in the HAC15 cell line ( $\sim 1.85$ fold-change) but lower in primary melanoma cells, suggesting that these cells may have distinct
DDR mechanisms. BRCA2 gene expression was significantly decreased only in primary melanoma cells $(\mathrm{P}<0.05)$. The expression of the XRCC4 gene was significantly reduced in HAC15 cells ( $\sim 0.56$ fold-change). No significant changes in the expression of PRKDC were observed in any of the treated cells.

Next, the type of cell death that was most likely to be activated after mitotane treatment was determined. The results indicate that it is probable that all the cells evaluated undergo necrosis more frequently than apoptosis (based on propidum iodide and cPARP staining, respectively). In the HAC15 cell line, a $\sim 60 \%$ increase in the number of cells undergoing necrosis was observed. The WM266-4 cell line also exhibited an elevated level of necrosis ( $44 \%$ of the mean fluorescence; $\mathrm{P}<0.01)$. A higher level of necrosis was observed in the primary melanoma cells $(\sim 72 \%)$ compared with that observed in the WM266-4 cell line $(\mathrm{P}<0.05)$ (Fig. 2C). The only cell line to demonstrate an elevated level (16\%) of apoptosis was HAC15 (P<0.05) (Fig. 2D). Similarly, the primary melanoma cells appeared to be less sensitive to mitotane, as evidenced by the absence of apoptosis. To confirm these results, the expression of the pro-/antiapoptotic genes BAX and BCL-2 was investigated. In the HAC15 cell line, these genes showed an elevated expression level in treated cells $(\sim 1.5$ fold-change for BAX and $~ 2.16$ fold-change for BCL-2) compared with that of the controls. WM266-4 cells were characterized by greater expression of the BCL-2 gene $(\sim 1.61$ fold-change; $\mathrm{P}<0.05)$. Importantly, no significant changes were observed in BAX or BCL-2 gene expression in the primary melanoma cells.

Cell cycle arrest at $\mathrm{G}_{1}$ occurred after mitotane administration in all the examined cell types, with $\leq 10 \%$ more cells present in the $\mathrm{G}_{1}$ phase of the cell cycle. Consequently, a smaller percentage of cells were detected in the $S$ and $G_{2}$ phases of the cell cycle. The largest changes $(\mathrm{P}<0.001)$ were observed in the WM266-4 cell line (Fig. 2E). These results were confirmed by RT-qPCR analysis, which was employed to analyze the expression of genes involved in the cell cycle (CDK2 and CDK4). An elevated level of CDK4 gene expression ( 3.8 fold-change) was observed in the HAC15 cells, which is characteristic of the $\mathrm{G}_{1}$ phase. The expression of the CDK2 gene was also found to be significantly reduced in the HAC15 and WM266-4 cell lines, with 0.4 and $\sim 0.5$ fold-change, respectively. Since CDK2 is responsible for $G_{1} / S$ and $S / G_{2}$ transitions (46), the present findings suggest that mitotane treatment reduces the number of cells in the $S$ and $G_{2}$ phases of the cell cycle. No changes were observed in the primary melanoma cells in terms of the expression of CDK2 or CDK4. However, cell cycle analysis by flow cytometry indicated arrest of these cells in the $\mathrm{G}_{1}$ phase of the cell cycle (with a $\sim 10 \%$ increase; Fig. 2E).

Mitotane at a dose of $50 \mu \mathrm{M}$ significantly modulates the transcriptomic profile of primary melanoma, WM226-4 and HAC15 cells. A transcriptome study was carried out after $24 \mathrm{~h}$ of cell incubation with mitotane and the results of the treated cells were compared with those of the untreated (control) group. The overall transcriptome profiles are shown as volcano plots in Fig. 3A. The following DEG selection criteria were used: IFold-changel (absolute value) $>1.5$ and P-value with FDR correction $<0.05$. According to the accepted cut-off criteria, in primary melanoma cells, 
A

a

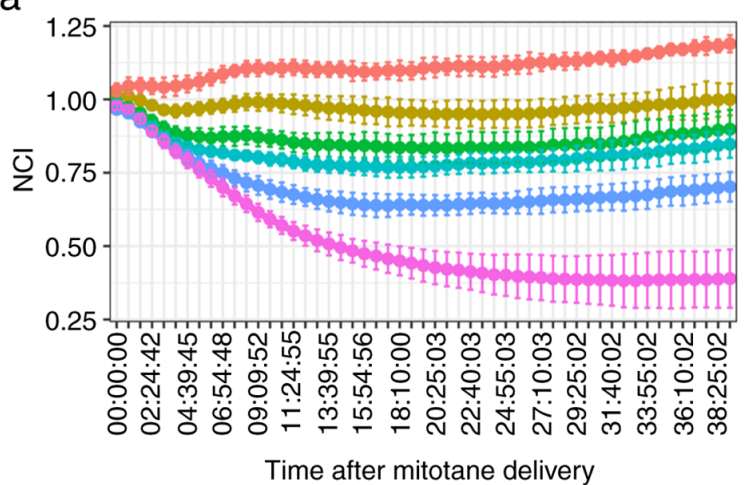

b

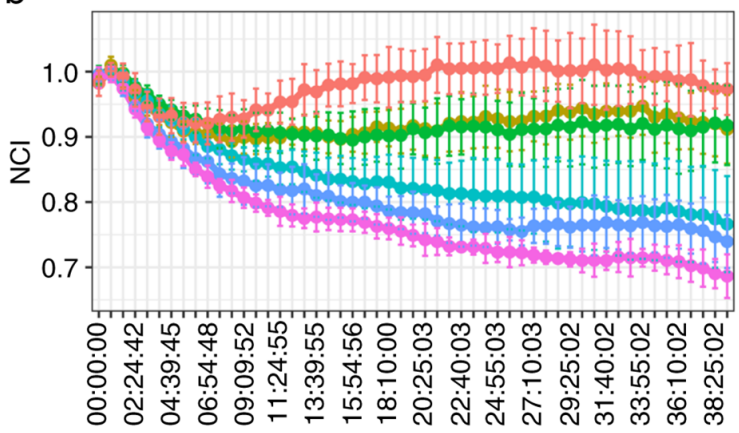

Time after mitotane delivery

C

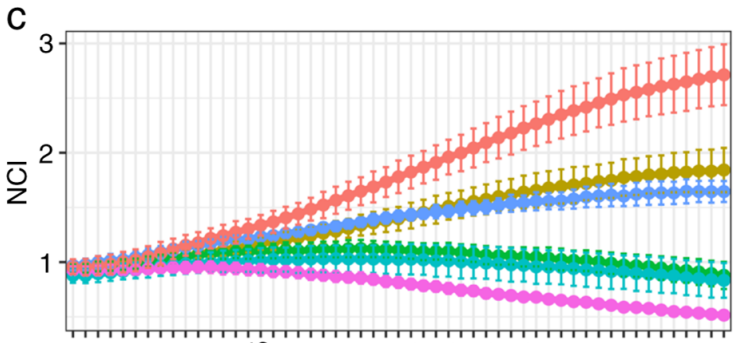

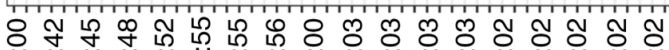

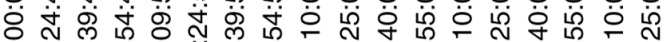

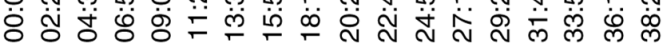
Time after mitotane delivery
B
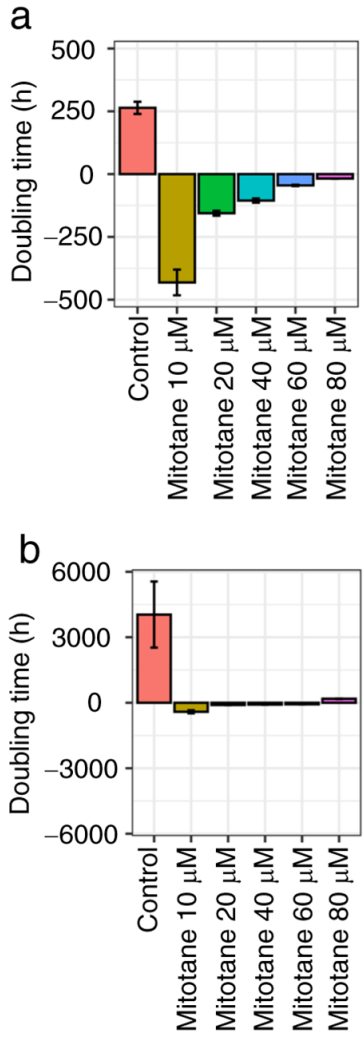

C

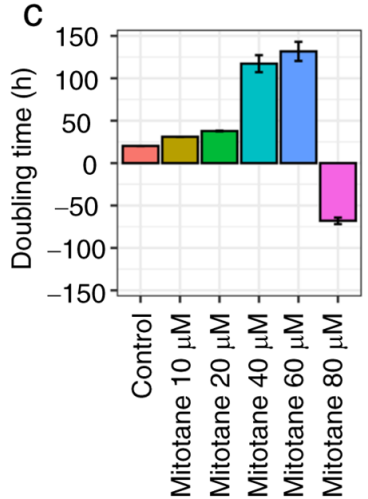

C

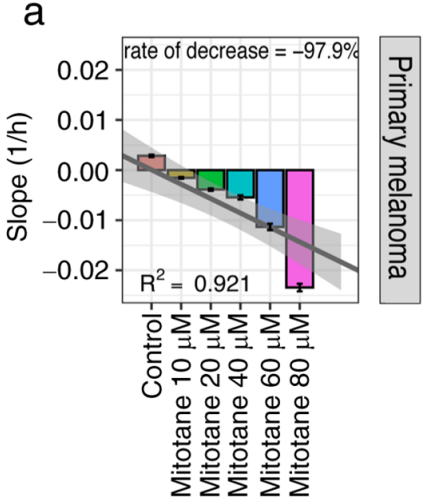

b
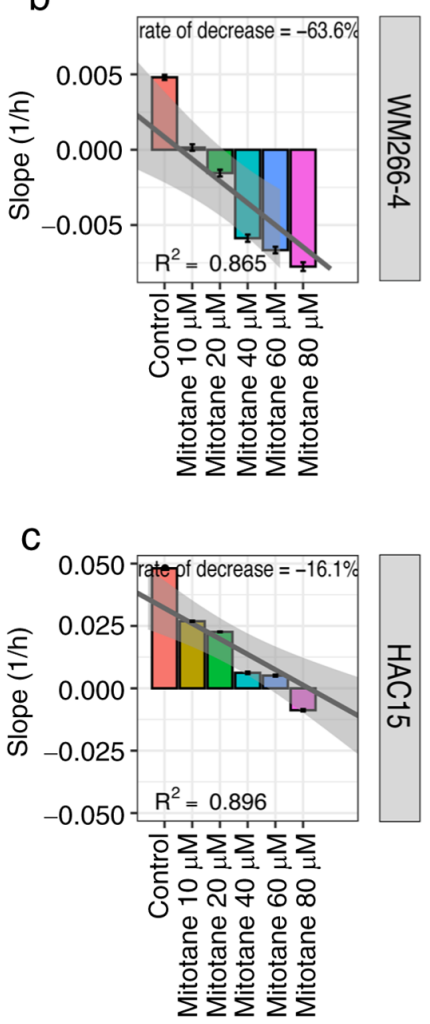

Control $\square$ Mitotane $10 \mu \mathrm{M} \square \quad$ Mitotane $20 \mu \mathrm{M} \square$

Mitotane $40 \mu \mathrm{M} \square \quad$ Mitotane $60 \mu \mathrm{M} \square$ Mitotane $80 \mu \mathrm{M}$

Figure 1. (A-C) Effect of mitotane at a concentration range of 10 to $80 \mu \mathrm{M}$ on the proliferation of (a) primary human melanoma cells, (b) the WM266-4 human melanoma cell line and (c) the HAC15 human adrenal carcinoma cell line. (A) Mean NCI determined during the culture period. (B) Doubling time (in h) measured during the first $24 \mathrm{~h}$ of culture after mitotane treatment. Positive values indicate the time required to double the NCI, while negative values indicate the time needed to reduce the NCI by half. (C) Slope of the proliferation curve based on the curve-fit in the first $24 \mathrm{~h}$ after mitotane treatment. Individual values were used for generating a linear regression model from which the rate of decrease was calculated. Regression lines with $95 \%$ confidence intervals and R-squared values are shown. NCI, normalized cell index.

mitotane induced a significant decrease in the expression of 21 genes, while it stimulated the expression of 17 genes. In the WM266-4 cell line, 47 genes were upregulated and 229 genes downregulated. The strongest effect of mitotane on transcriptome modulation was observed in HAC15 cells, where mitotane stimulated and inhibited the expression of 466 and 411 genes, respectively.

The 10 genes with the highest and lowest fold-change values are presented in a tabular format in Fig. 3B. In primary melanoma cells, this group of genes includes aldehyde dehydrogenase 1 family member L2 (fold-change=2.42) and mitochondrial MT-RNR2-like 2 gene (fold-change=-3.25). In the WM266-4 cell line, mitotane most strongly influenced the expression of the following genes: Matrix metallopeptidase 1 (fold-change $=3.25$ ), zinc finger and BTB domain containing 20 (fold-change=-3.06) and ST8 $\alpha$-N-acetyl-neuraminide $\alpha$-2,8-sialyltransferase 6 (fold-change=-3.06) (belonging to the protein family that synthesizes sialyl glycoconjugates), which are involved in multidrug resistance in cancer cells (47). In the ACC HAC15 
A

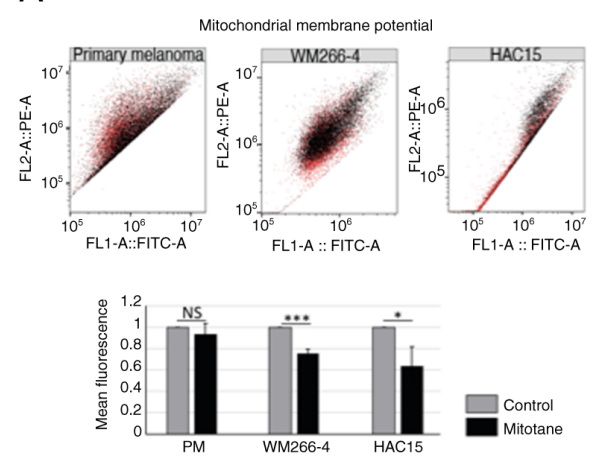

B
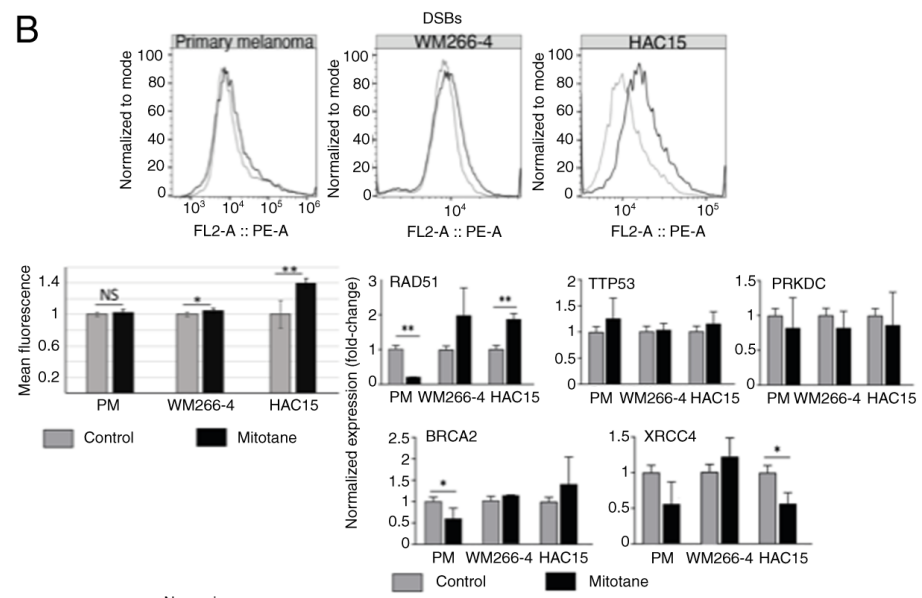

C

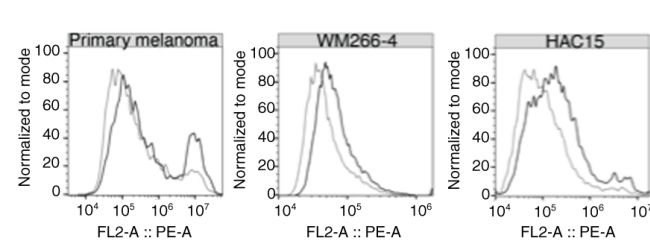

Necrosis

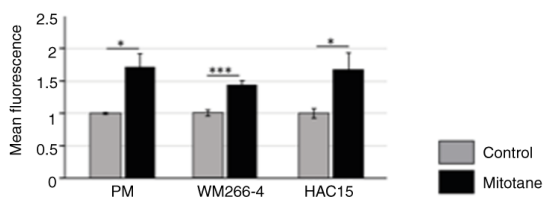

D
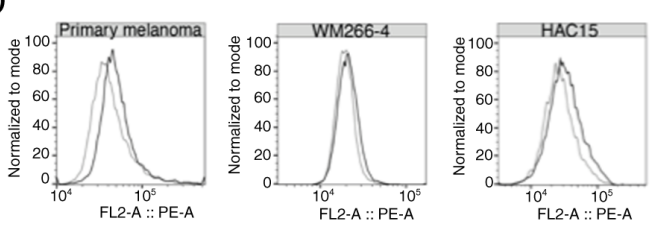

Apoptosis
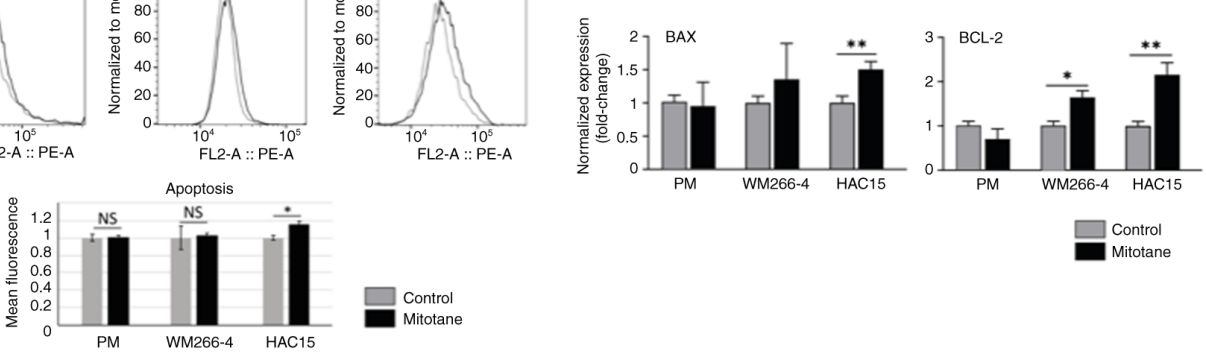

E
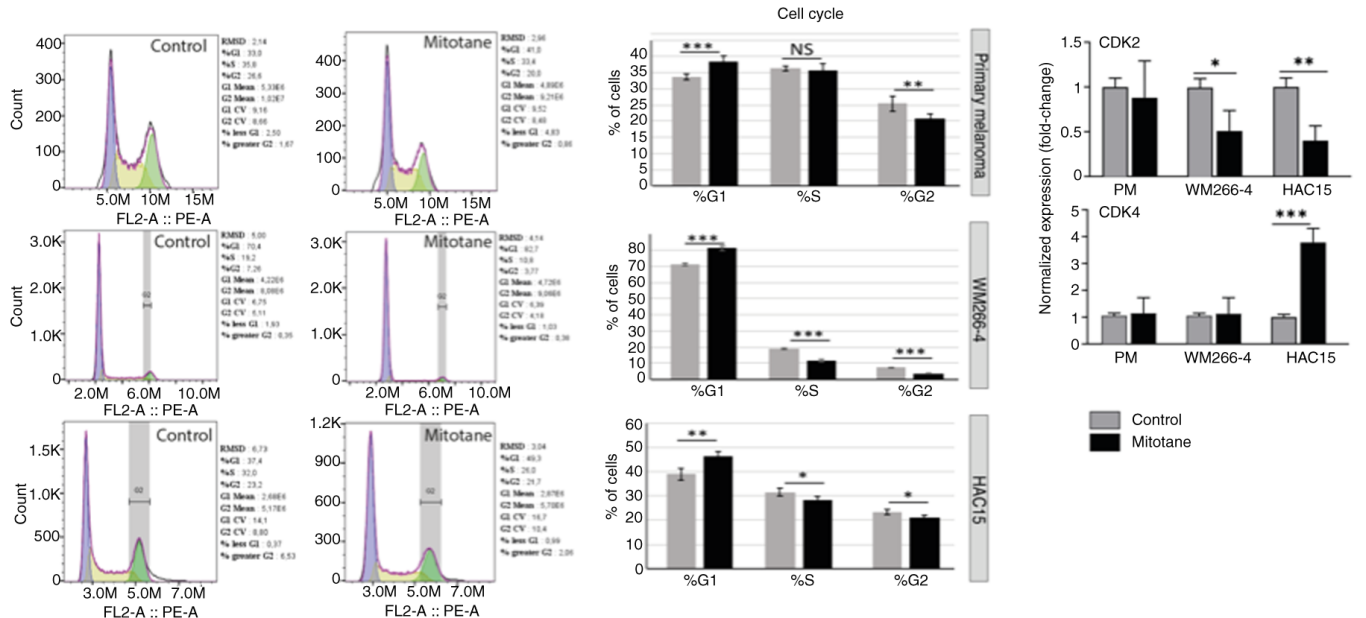

$\square$ Control

Figure 2. Effect of mitotane on mitochondrial membrane potential. (A) The black and red colors reflect the changes shown in the chart below, where the black color corresponds to the untreated control and the red color indicates changes in red fluorescence after mitotane treatment. In the WM266-4 and HAC15 cell lines, significant changes in red fluorescence were observed $(\mathrm{P}<0.001$ and $\mathrm{P}<0.05$, respectively). By contrast, primary melanoma cells showed no significant changes in fluorescence intensity. (B) The most significant change in DSBs (as reflected $\gamma \mathrm{H} 2 \mathrm{AX}$ expression) was observed in the HAC15 cell line ( 40\% increase; $\mathrm{P}<0.01)$. The WM266-4 cell line also showed a notable increase in DSBs formation $(\sim 10 \% ; \mathrm{P}<0.05)$. Primary melanoma cells showed no significant change in the number of DSBs. Analysis of the expression of genes involved in DNA damage response showed that the HAC15 cell line may promote homologous recombination (RAD51, 1.85 fold-change). Primary melanoma cells showed decreased gene expression of BRCA2 ( 0.6 fold-change) and RAD51 ( 0.2 fold-change). No significant changes in gene expression of TTP53 or PRKDC were observed in any of the cell types evaluated. (C) In all the investigated cell types, an elevated level of necrosis was observed: $72 \%$ (primary melanoma), 44\% (WM266-4) and 60\% (HAC15). (D) Apoptosis was analyzed via flow cytometry detecting cleaved PARP-1. The HAC15 cell line presented significantly higher levels of pro-apoptotic markers (BAX) and antiapoptotic markers (BCL-2) compared with those of other cell types. Specifically, BAX and BCL-2 gene expression was significantly increased in HAC15 cells ( $\sim 1.5$ and $\sim 2.16$ fold-change, respectively). The WM266-4 cell line also showed an elevated level of BCL-2 gene expression ( 1.61 fold-change; $\mathrm{P}<0.05)$. (E) All the investigated cell types (primary melanoma, WM266-4 and HAC15) showed a higher percentage of cells in the G1 phase of the cell cycle, as follows: From $\sim 33.72$ to $\sim 38.53 \%$ in primary melanoma cells; from $\sim 71.22$ to $\sim 81.15 \%$ in WM266-4 cells; and from $\sim 38.95$ to $\sim 46.40 \%$ in HAC15 cells. The CDK2 and CDK4 genes showed, respectively, decreased and increased expression levels. The most notable changes were observed in the HAC15 and WM266-4 cell lines [CDK2, 0.4 fold-change (HAC15) and 0.5 fold-change (WM266-4); and CDK4, 3.8 fold-change (HAC15)]. Primary melanoma cells did not show a significant change in the expression of these genes. ${ }^{*} \mathrm{P}<0.05,{ }^{* *} \mathrm{P}<0.01,{ }^{* * *} \mathrm{P}<0.001$. DSB, DNA double-strand breaks; RAD51, RAD51 recombinase; BRCA2, breast cancer type 2 susceptibility protein; PRKDC, protein kinase, DNA-activated, catalytic subunit; PM, primary melanoma. 
A
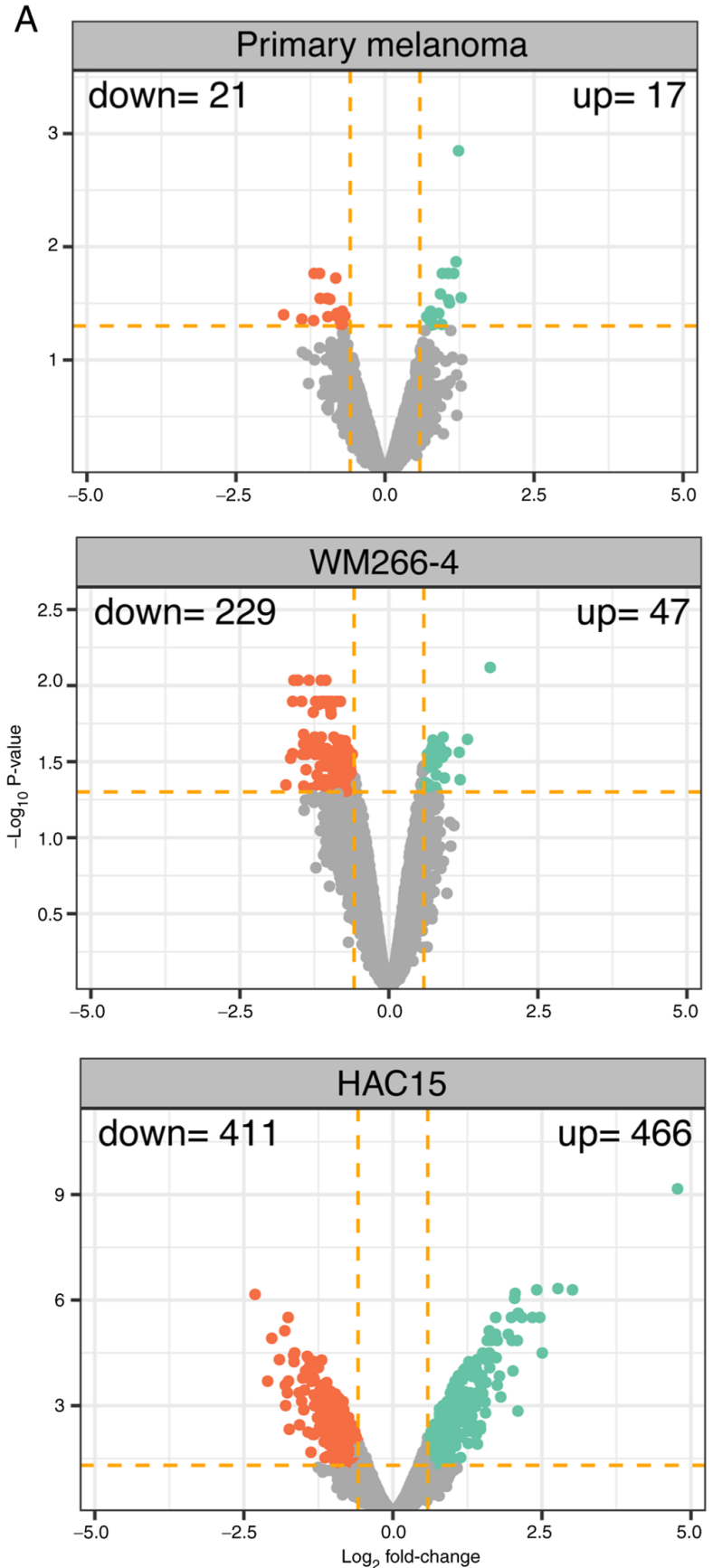

$B$

\begin{tabular}{|c|c|c|c|}
\hline Gene symbol & Gene name & Fold-change & adj. P.val \\
\hline ALDH1L2 & Aldehyde dehydrogenase 1 family member $L 2$ & 2.42 & $2.82 \times 10^{-2}$ \\
\hline CHAC1 & ChaC glutathione specific gamma-glutamylcyclotransferase 1 & 2.35 & $1.42 \times 10^{-3}$ \\
\hline ANKRD30B & Ankyrin repeat domain $30 \mathrm{~B}$ & 2.29 & $1.35 \times 10^{-2}$ \\
\hline DDIT3 & DNA damage inducible transcript 3 & 2.22 & $1.72 \times 10^{-2}$ \\
\hline MMP3 & Matrix metallopeptidase 3 & 2.12 & $3.13 \times 10^{-2}$ \\
\hline MIR29A & MicroRNA 29a & 2.09 & $2.94 \times 10^{-2}$ \\
\hline FKBP1AP1 & FKBP prolyl isomerase $1 \mathrm{~A}$ pseudogene 1 & 2.09 & $1.72 \times 10^{-2}$ \\
\hline PSAT1 & Phosphoserine aminotransferase 1 & 1.95 & $1.72 \times 10^{-2}$ \\
\hline LURAP1L-AS1 & LURAP1L antisense RNA 1 & 1.94 & $4.86 \times 10^{-2}$ \\
\hline SLC7A11 & Solute carrier family 7 member 11 & 1.91 & $2.61 \times 10^{-2}$ \\
\hline CLDN18 & Claudin 18 & -1.90 & $2.91 \times 10^{-2}$ \\
\hline HOXD12 & Homeobox D12 & -1.94 & $4.14 \times 10^{-2}$ \\
\hline PADI3 & Peptidyl arginine deiminase 3 & -1.95 & $2.86 \times 10^{-2}$ \\
\hline KIAA0040 & KIAA0040 & -1.97 & $2.86 \times 10^{-2}$ \\
\hline IFNA14 & Interferon alpha 14 & -2.13 & $2.86 \times 10^{-2}$ \\
\hline PPP1R1A & Protein phosphatase 1 regulatory inhibitor subunit $1 \mathrm{~A}$ & -2.14 & $1.72 \times 10^{-2}$ \\
\hline BHLHA15 & Basic helix-loop-helix family member a15 & -2.28 & $1.72 \times 10^{-2}$ \\
\hline MIR378I & MicroRNA 378i & -2.29 & $4.49 \times 10^{-2}$ \\
\hline MIR3194 & MicroRNA 3194 & -2.63 & $4.36 \times 10^{-2}$ \\
\hline MTRNR2L2 & MT-RNR2 like 2 & -3.25 & $3.99 \times 10^{-2}$ \\
\hline
\end{tabular}

\begin{tabular}{|c|c|c|c|}
\hline Gene symbol & Gene name & Fold-change & adj. P.val \\
\hline MMP1 & Matrix metallopeptidase 1 & 3.25 & $7.61 \times 10^{-3}$ \\
\hline KRTAP10-1 & Keratin associated protein 10-1 & 2.49 & $2.26 \times 10^{-2}$ \\
\hline MIR1234 & MicroRNA 1234 & 2.29 & $4.16 \times 10^{-2}$ \\
\hline ST8SIA5 & ST8 alpha-N-acetyl-neuraminide alpha-2,8-sialyltransferase 5 & 2.26 & $2.75 \times 10^{-2}$ \\
\hline MIR1976 & MicroRNA 1976 & 1.94 & $2.75 \times 10^{-2}$ \\
\hline SLC38A1 & Solute carrier family 38 member 1 & 1.91 & $4.05 \times 10^{-2}$ \\
\hline LOC102724467 & Uncharacterized LOC102724467 & 1.88 & $2.18 \times 10^{-2}$ \\
\hline ITGA11 & Integrin subunit alpha 11 & 1.86 & $2.96 \times 10^{-2}$ \\
\hline ASNS & Asparagine synthetase (glutamine-hydrolyzing) & 1.81 & $2.54 \times 10^{-2}$ \\
\hline GADD45B & Growth arrest and DNA damage inducible beta & 1.81 & $2.83 \times 10^{-2}$ \\
\hline PCDHB4 & Protocadherin beta 4 & -2.69 & $2.42 \times 10^{-2}$ \\
\hline LOC105373730 & Uncharacterized LOC105373730 & -2.70 & $2.09 \times 10^{-2}$ \\
\hline LOC102724642 & Anaphase-promoting complex subunit 1-like & -2.73 & $2.83 \times 10^{-2}$ \\
\hline APOE & Apolipoprotein E & -2.76 & $1.27 \times 10^{-2}$ \\
\hline ZNF441 & Zinc finger protein 441 & -2.87 & $9.23 \times 10^{-2}$ \\
\hline ABCA1 & ATP binding cassette subfamily A member 1 & -3.02 & $9.23 \times 10^{-2}$ \\
\hline ZBTB20 & Zinc finger and BTB domain containing 20 & -3.06 & $1.27 \times 10^{-2}$ \\
\hline ST8SIA6 & ST8 alpha-N-acetyl-neuraminide alpha-2,8-sialytltransterase 6 & -3.06 & $2.80 \times 10^{-2}$ \\
\hline LOC101060632 & Uncharacterized LOC101060632 & -3.14 & $3.00 \times 10^{-2}$ \\
\hline FAM72D & Family with sequence similarity 72 member D & -3.31 & $4.50 \times 10^{-2}$ \\
\hline & & & \\
\hline
\end{tabular}

\begin{tabular}{|c|c|c|c|}
\hline Gene symbol & Gene name & Fold-change & adj. P.val \\
\hline GDF15 & Growth differentiation factor 15 & 27.38 & $6.86 \times 10^{-10}$ \\
\hline DDIT3 & DNA damage inducible transcript 3 & 8.07 & $5.11 \times 10^{-7}$ \\
\hline FABP2 & Fatty acid binding protein 2 & 6.81 & $4.70 \times 10^{-7}$ \\
\hline NID1 & Nidogen 1 & 5.68 & $3.19 \times 10^{-5}$ \\
\hline DLGAP1-AS2 & DLGAP1 antisense RNA 2 & 5.52 & $3.12 \times 10^{-6}$ \\
\hline TRIB3 & Tribbles pseudokinase 3 & 5.33 & $5.11 \times 10^{-7}$ \\
\hline SESN2 & Sestrin 2 & 5.07 & $3.12 \times 10^{-6}$ \\
\hline NUPR1 & Nuclear protein 1, transcriptional regulator & 4.48 & $3.12 \times 10^{-6}$ \\
\hline ARG2 & Arginase 2 & 4.29 & $2.36 \times 10^{-6}$ \\
\hline BEST1 & Bestrophin 1 & 4.28 & $1.43 \times 10^{-3}$ \\
\hline CXCR4 & C-X-C motif chemokine receptor 4 & -3.37 & $2.01 \times 10^{-4}$ \\
\hline MIR889 & MicroRNA 889 & -3.38 & $3.12 \times 10^{-6}$ \\
\hline TUBB4A & Tubulin beta 4A class IVa & -3.41 & $4.32 \times 10^{-4}$ \\
\hline MEI4 & Meiotic double-stranded break formation protein 4 & -3.48 & $9.96 \times 10^{-4}$ \\
\hline SNORD114-13 & Small nucleolar RNA, C/D box 114-13 & -3.50 & $2.63 \times 10^{-4}$ \\
\hline GNRHR & Gonadotropin releasing hormone receptor & -3.52 & $7.47 \times 10^{-6}$ \\
\hline MIR376B & MicroRNA 376b & -3.74 & $4.92 \times 10^{-5}$ \\
\hline HSD3B2 & Hydroxy-delta-5-5-teroid dehydrogenase, 3 beta-and steroid delta-isomerase 2 & -4.09 & $1.22 \times 10^{-5}$ \\
\hline SNORD114-10 & Small nucleolar RNA, C/D box 114-10 & -4.29 & $2.02 \times 10^{-4}$ \\
\hline LDLR & Low density lipoprotein receptor & -4.97 & $6.90 \times 10^{-7}$ \\
\hline & & & \\
\hline
\end{tabular}

Figure 3. Total gene expression profile of primary human melanoma cells, WM266-4 (a human melanoma cell line) and HAC15 (a human adrenal carcinoma cell line) after a 24-h incubation with mitotane $(50 \mu \mathrm{M})$ compared with that of control (untreated) cells. (A) Volcano plots, where each dot represents a mean normalized expression from a single gene. Dotted orange lines indicate cut-off values ( 1.5 fold-change in expression and $\mathrm{P}<0.05$ with false discovery rate correction). The red dots represent downregulated genes meeting the cut-off criteria, while the green dots represent upregulated genes. The cumulative value of upregulated and downregulated genes is shown in the upper corners of the diagrams. (B) Tables with the top 20 most upregulated or downregulated genes (10 upregulated and 10 downregulated), showing the relevant genes with their fold-change and adjusted P-values, in each of the cell types investigated. Adj. P.val, adjusted P-value.

cell line, mitotane significantly stimulated the expression of growth differentiation factor 15 (fold-change=27.38), a major secretory protein induced by mitochondrial dysfunction (48), and DNA damage inducible transcript 3 (DDIT3; fold-change $=8.07$ ), an endoplasmic reticulum stress-induced apoptosis factor (49). In HAC15 cells, mitotane most potently inhibited the expression of genes involved in adrenal steroidogenesis, such as low-density lipoprotein receptor (fold-change=-4.97).
Mitotane at dose of $50 \mu \mathrm{M}$ exerts a significant effect on genes involved in the cell division in both WM266-4 and HAC15 cells. This analysis was performed separately for the previously obtained DEGs from individual comparisons using the DAVID bioinformatics tools. The results of this analysis are shown as bubble plots in Fig. 4A, which contain only those ontological groups that met the following criteria: Adjusted $\mathrm{P}<0.05$ and $\geq 5$ genes in the group. In primary melanoma cells, none of the ontological groups met these criteria; however, in these cells, 
A

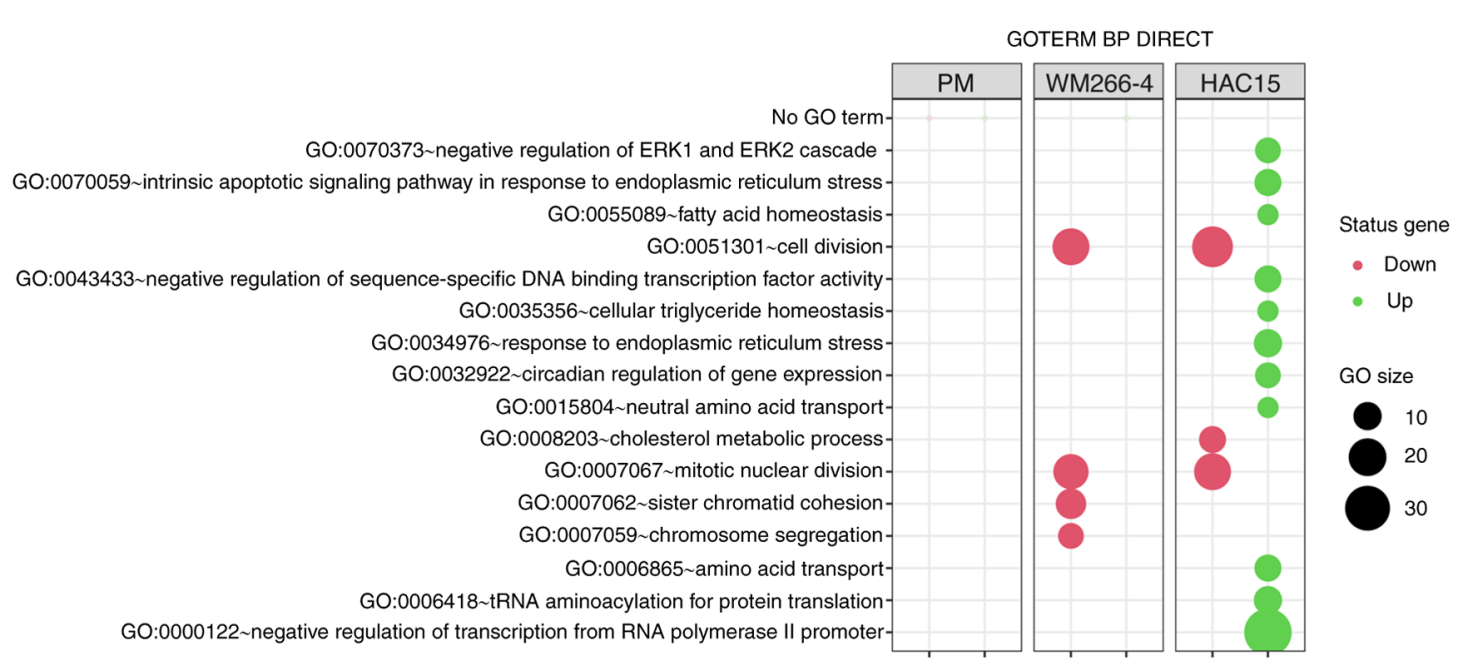

$\mathrm{B}$
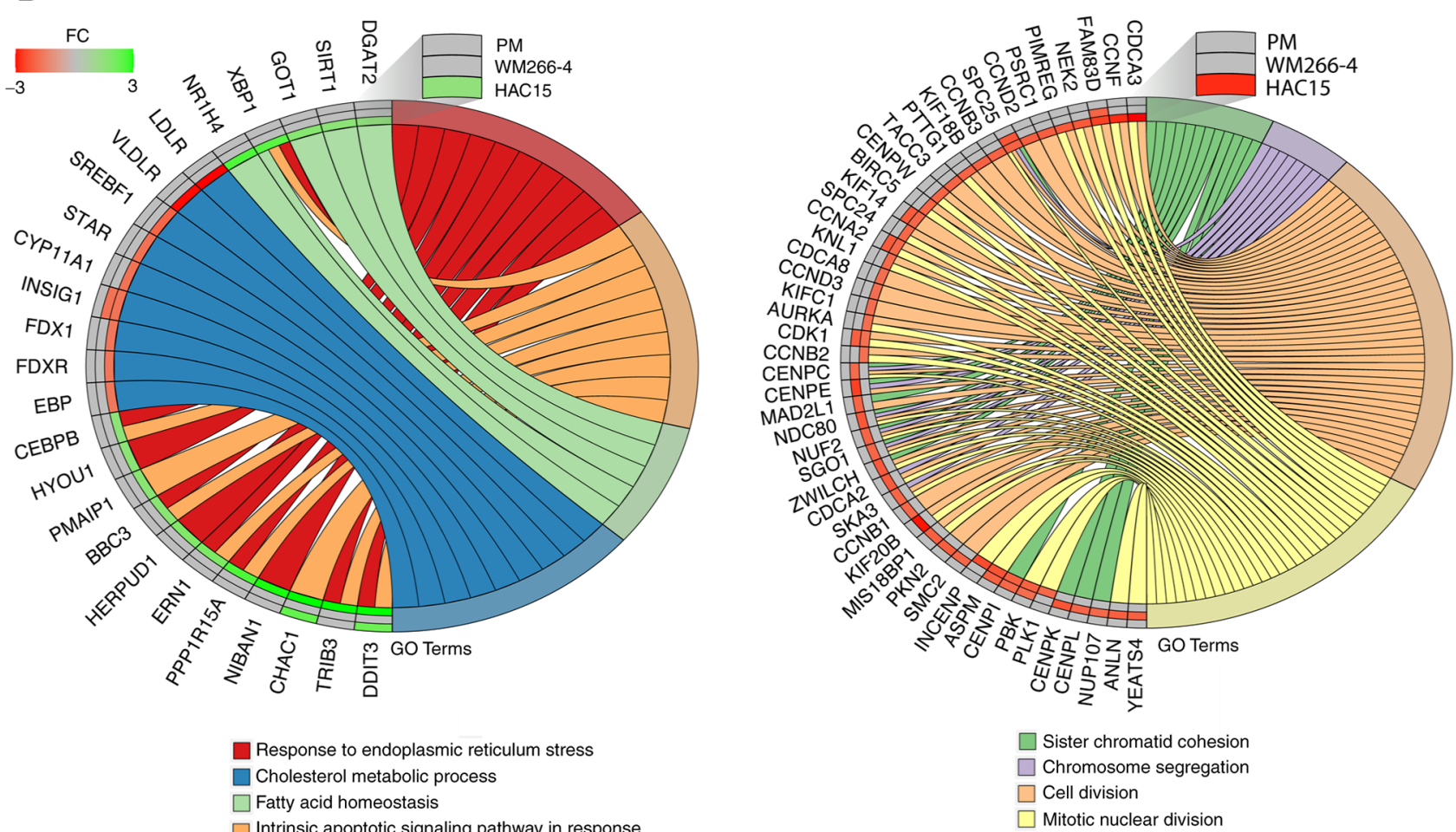

Figure 4. (A) Bubble plot of DEG sets overrepresented in the DAVID GO-BP DIRECT database. The graph shows only the GO terms above the established cut-off criteria (corrected $\mathrm{P}<0.05$ and $>5$ genes per group). Each bubble's size reflects the number of DEGs assigned to the GO-BP terms. The bubble's transparency displays $\mathrm{P}$-values (more transparent indicates closer to the $\mathrm{P}=0.05$ cut-off value). The red color indicates downregulated expression of the genes comprising the relevant GO term, while the green color indicates upregulation of such genes. (B) Detailed analysis of eight enriched gene ontological groups selected from the DAVID GO-BP DIRECT GO database, presented as Circos plots. Symbols of DEGs are presented on the left side of the graph with their fold-change values, mapped by color scale, where green indicates higher expression, red indicates lower expression and grey indicates expression levels below the cut-off value for a given cell type. Colored connecting lines determine gene involvement in the GO terms. GO, Gene Ontology; DAVID, Database for Annotation, Visualization and Integrated Discovery; BP, biological process; DEG, differentially expressed gene; PM, primary melanoma; FC, fold-change.

only a limited number of DEGs (21 upregulated and 17 downregulated) were used for the analysis. In the WM266-4 cell line, mitotane inhibited genes belonging to ontological groups associated with cell proliferation such as 'GO:0007067 mitotic nuclear division', (n=17; $\left.\mathrm{P}=7.83 \times 10^{-6}\right)$; 'GO:0007062 sister chromatid cohesion' ( $\left.\mathrm{n}=12 ; \mathrm{P}=7.83 \times 10^{-6}\right)$; 'GO:0051301 cell division' ( $\left.\mathrm{n}=19 ; \mathrm{P}=1.74 \times 10^{-5}\right)$ and 'GO:0007059 chromosome segregation' ( $\mathrm{n}=8 ; \mathrm{P}=0.002)$. In HAC15 cells, decreased expression was also observed in genes belonging to proliferation-related ontology groups, including: 'GO:0008203 cholesterol metabolic process' $\left(\mathrm{n}=9 ; \mathrm{P}=4.14 \times 10^{-4}\right)$, 'GO:0051301 cell division' $(\mathrm{n}=24$; $\left.\mathrm{P}=9.01 \times 10^{-5}\right)$ and 'GO:0007067 mitotic nuclear division' ( $\mathrm{n}=19$; $\mathrm{P}=3.11 \times 10^{-4}$ ). In the HAC15 cell line, mitotane also stimulated the expression of genes belonging to the following ontology groups, which are key for the present study due to the fact that they are directly involved in the processes associated with the action of cytostatics: 'GO:0070059 intrinsic apoptotic signaling pathway in response to endoplasmic reticulum stress' $(n=9 ; P=0.0003)$, 
A

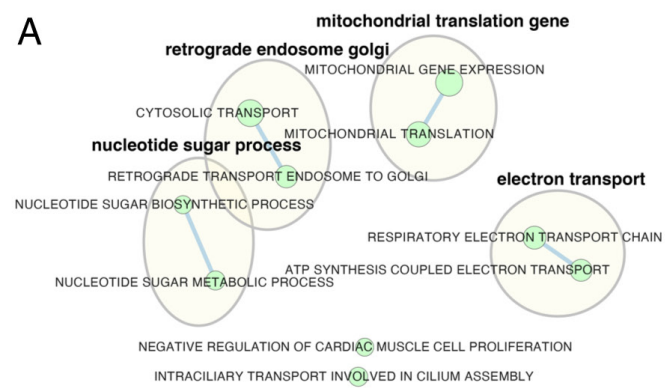

C

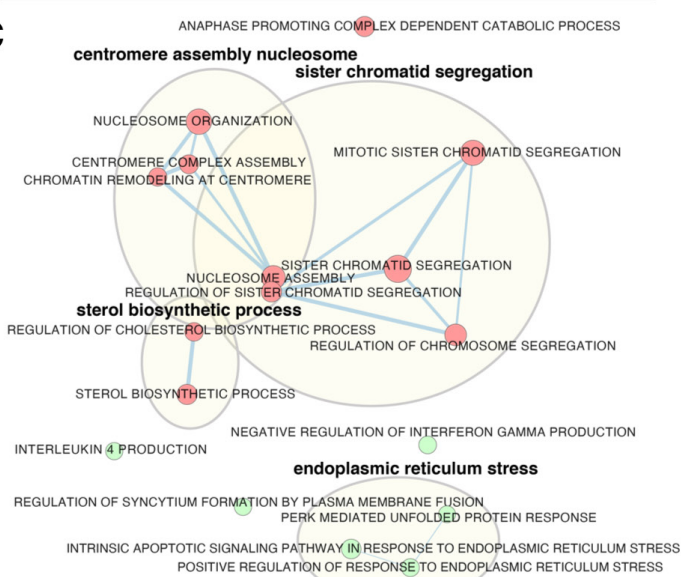

B

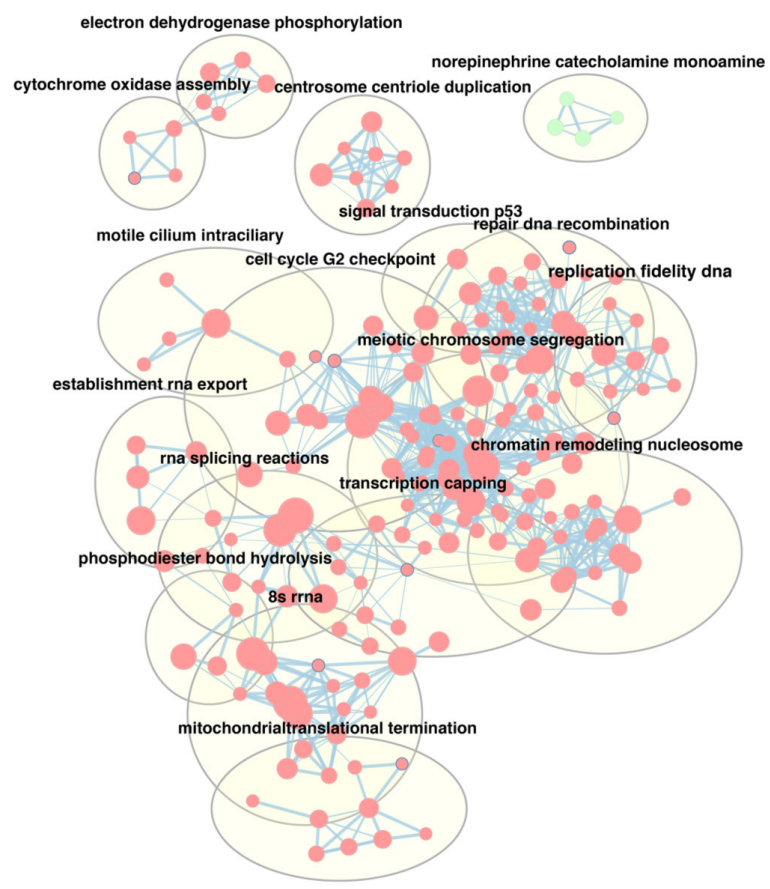

Figure 5. Gene set enrichment analysis of (A) primary human melanoma cells, (B) WM266-4, human melanoma cell line and (C) HAC15 human adrenal carcinoma cell line after a 24-h incubation with mitotane $(50 \mu \mathrm{M})$ compared with that of control (untreated) cells. The diagram shows the enrichment map of significantly changed terms (green indicates increased while read indicates reduced; adjusted $\mathrm{P}<0.05$ ). The thickness of the connecting line indicates the level of genes matching to individual terms.

'GO:0034976 response to endoplasmic reticulum stress' ( $\mathrm{n}=10$; $\mathrm{P}=0.009)$ and 'GO:0070373 negative regulation of ERK1 and ERK2 cascade' $(n=8 ; P=0.04)$. A detailed analysis of genes assigned to several ontology groups is shown in two circos plots in Fig. 4B. Several of these genes exhibited expression changes above the cut-off threshold in the two comparison groups, including DDIT3 (primary melanoma cells: Fold-change $=2.22$; HAC15 cells: Fold-change $=8.1$ ); kinesin family member 14 (KIF14; WM266-4 cells: Fold-change $=-1.83$; HAC15 cells: Fold-change $=-1.64$ ); cyclin A2 (CCNA2; WM266-4 cells: Fold-change $=-1.84$; HAC15 cells: Fold-change $=-1.62$ ); cyclin dependent kinase 1 (CDK1; WM266-4 cells: Fold-change=-1.76; HAC15 cells: Fold-change $=-1.51$ ) and centromere protein I (CENPI; WM266-4 cells: Fold-change $=-1.63$; HAC15 cells: Fold-change $=-1.74$ ).

Only a relatively limited number of genes involved in cell proliferation and apoptosis were regulated in a similar manner by mitotane (regardless of the cell type). Consequently, an alternative bioinformatic evaluation of transcriptome modulation was performed by using GSEA. This approach was based on full transcriptomic profile analysis regardless of the predefined cut-off criteria (fold-change $>2, \mathrm{P}<0.05$ ). In this approach, genes pre-ranked by logarithmic fold-change values were employed to determine enrichment [positive normalized enrichment score (NES)] or depletion (negative NES) in the GO-BP database after mitotane treatment.

In primary melanoma cells (Fig. 5A), mitotane treatment led, inter alia, to the enrichment of genes involved in the regulation of mitochondrial gene expression ('mitochondrial gene expression', NES=1.96; 'mitochondrial translocation', NES=2.02), as well as genes responsible for electron transport ('respiratory electron transport', NES=2; ATP synthesis coupled electron transport, NES=1.98).

The largest number of significantly regulated ontology groups obtained with GSEA analysis was observed in the WM266-4 cell line; thus, only the names of ontology term clusters obtained by using the AutoAnnotate Cytoscape plugin are shown in Fig. 5B. The highest absolute NES values were as follows: 'Recombinational repair' (NES=-2.73); 'double strand break repair' (NES=-2.65), 'centromere complex assembly' (NES $=-2.64)$ and 'mitotic sister chromatid segregation' (NES=-2.63).

Despite using a different methodological approach in HAC15 cells, the GSEA analysis revealed relatively similar groups to those shown after the analysis of ontological groups (DAVID), with enrichment of genes belonging to apoptosis-related ontological groups, including 'intrinsic apoptotic signaling pathway in response to endoplasmic reticulum stress' $(\mathrm{NES}=2.1)$ and 'positive regulation of response to endoplasmic reticulum stress' (NES=2.19).

In HAC15 cells, genes belonging to proliferation and steroidogenesis-related ontology terms were depleted. The following groups had the highest absolute NES values: 'Anaphase promoting complex dependent catabolic process' $(\mathrm{NES}=-2.45)$, 'sterol biosynthetic process' $(\mathrm{NES}=-2.24)$, 'nucleosome assembly' (NES=-2.2), 'regulation of cholesterol biosynthetic process' (NES=-2.18) and 'mitotic sister chromatid segregation' (NES=-2.09) (Fig. 5C). 
A

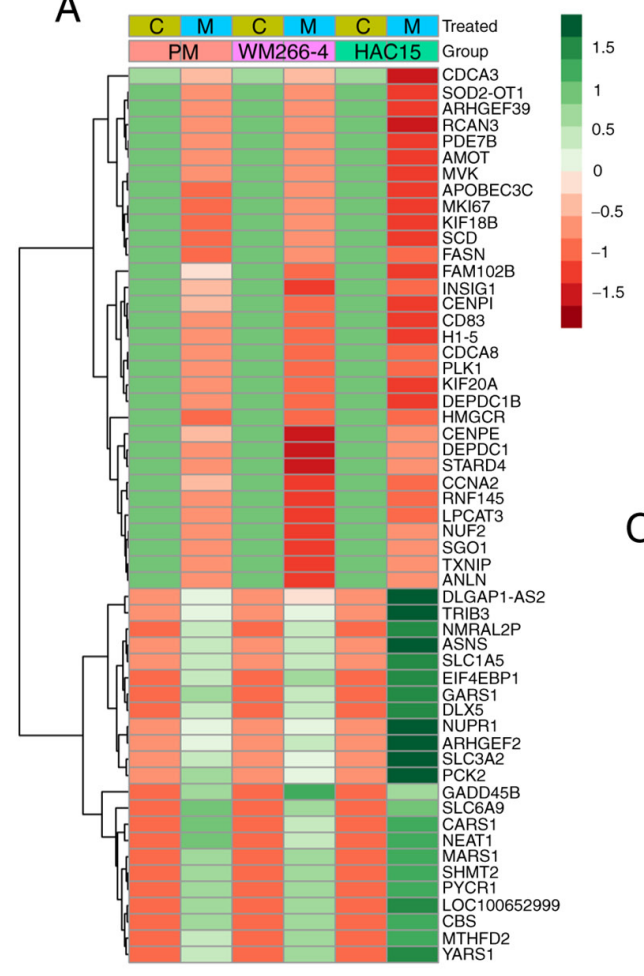

B

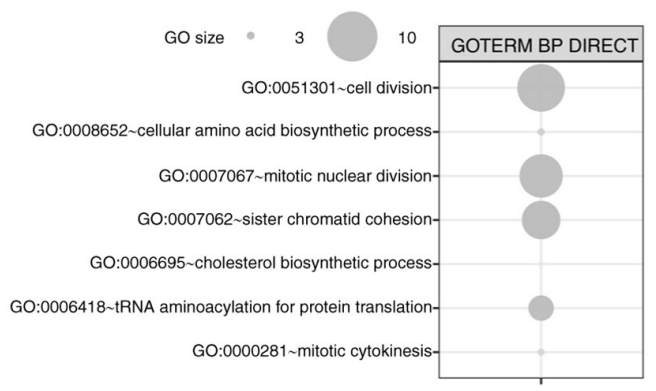

C

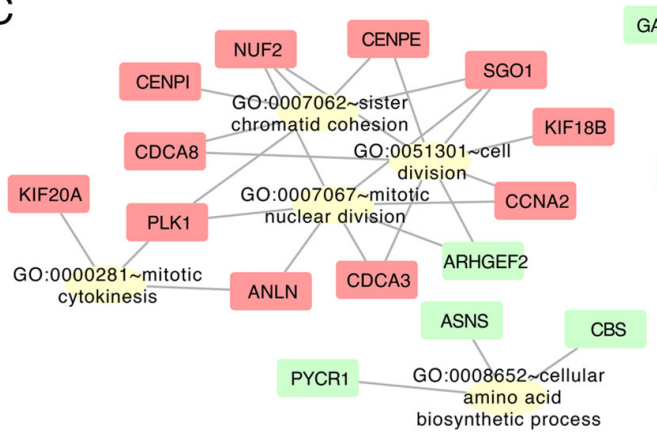

GARS1

GO:0006418 tRNA aminoacylation for protein transtation

MARS1 YARS

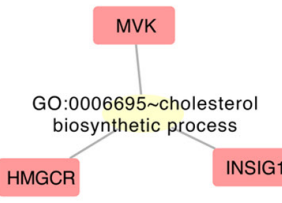

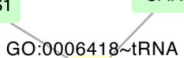

Figure 6. Genes controlled in the same manner in each of the evaluated cells after $24 \mathrm{~h}$ of incubation with mitotane (50 $\mu \mathrm{M})$ compared with those of control cells (untreated). Genes were selected to ensure that $\geq 1$ comparison met the previously assumed cut-off criteria. (A) Heatmap of fold-change values with hierarchical clustering. (B) Analysis of participation in specific ontological groups from the Database for Annotation, Visualization and Integrated Discovery GOTERM BP DIRECT database. (C) Interaction between genes and their GO terms. Increased expression is shown in green and decreased expression in red. $\mathrm{C}$, control; M, mitotane; GO, Gene Ontology; BP, biological process; PM, primary melanoma.

Since the GO analyses performed with DAVID and GSEA indicated differences between cell types, similar gene regulation under less restrictive selection conditions was evaluated. Genes for which the fold-change value for $\geq 1$ group was above the cut-off value (Ifold-changel $>1.5$ ), and the fold-change for the other groups had the same direction (positive or negative) and was within the range of 1.2 to 1.5 were selected. Fold-change values for these genes were transformed into z-scores and presented on a heatmap in Fig. 6A.

To identify the biological role of the selected genes, another GO analysis was performed using DAVID. Interactions between individual genes and relevant GO terms were evaluated with Cytoscape v.3.7.2. The largest cluster of ontology terms involved processes associated with cell division ('sister chromatid cohesion', 'cell division', 'mitotic nuclear division', 'nuclear division' and 'mitotic cytokinesis'), where most genes were downregulated (Fig. 6B). The ontological groups included the following genes: KIF20A (primary melanoma cells: Fold-change $=-1.41 ;$ WM266-4 cells: Fold-change $=-1.67$; HAC15 cells: Fold-change $=-2.1$ ), polo like kinase 1 (PLK1; primary melanoma cells: Fold-change $=-1.32$; WM266-4 cells: Fold-change $=-1.45$; HAC15 cells: Fold-change=-1.62), cell division cycle associated 8 (CDCA8; primary melanoma cells: Fold-change $=-1.22$; WM266-4 cells: fold-change $=-1.42$; HAC15 cells: Fold-change $=-1.54$ ), CENPI (primary melanoma cells: Fold-change $=-1.24 ; \mathrm{WM} 266-4$ cells: Fold-change $=-1.63$; HAC15 cells: Fold-change $=-1.74$ ), shugoshin 1 (SGO1; primary melanoma cells: Fold-change $=-1.23$; WM266-4 cells: Fold-change $=-1.66$; HAC15 cells: Fold-change $=-1.24)$, KIF18B (primary melanoma cells: Fold-change=-1.38; WM266-4 cells: Fold-change $=-1.21$; HAC15 cells: Fold-change=-1.7), CCNA2 (primary melanoma cells: Fold-change $=-1.23$; WM266-4 cells: Fold-change $=-1.83$; HAC15 cells: Fold-change $=-1.62$ ), Rho/Rac guanine nucleotide exchange factor 2 (primary melanoma cells: Fold-change $=1.24$; WM266- 4 cells: Fold-change $=1.39 ;$ HAC15 cells: Fold-change $=3.3$ ) and cell division cycle-associated 3 (primary melanoma cells: Fold-change $=-1.2 ; \mathrm{WM} 266-4$ cells: Fold - change $=-1.27$; HAC15 cells: Fold-change=-2.5) (Fig. 6C).

The hypothesis that there may be a link between the expression of a potential biomarker and disease progression was verified using expression data from TCGA database (94 and 470 cases of ACC and SKCM, respectively), which were analyzed for the predictive significance of genes commonly regulated by mitotane. Fig. 7 shows genes for which elevated expression may be a negative predictor of tumour progression for both ACC and SKCM. These genes include CCNA2, CDCA3, CDCA8, PLK1, CENPI and SGOL1.

\section{Discussion}

In our previous study (17), a patient was diagnosed with metastatic melanoma in the left adrenal gland of unknown primary origin and received mitotane treatment. On follow-up, there was no sign of recurrence in the adrenal bed. At the 3-month follow-up after mitotane withdrawal, multiple metastases were identified. Thus, in the present study, experiments were conducted on an in vitro model using HAC15 (adrenal 
A

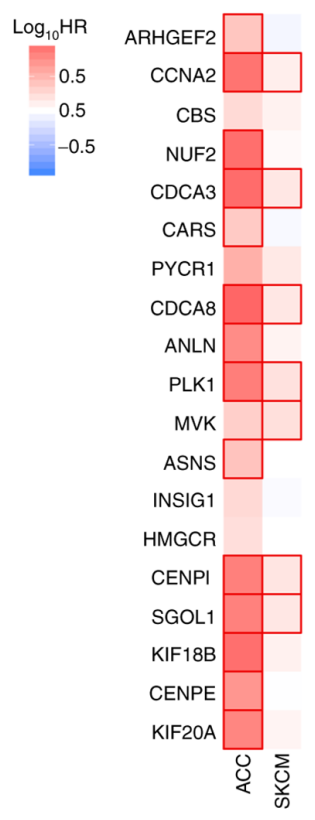

B
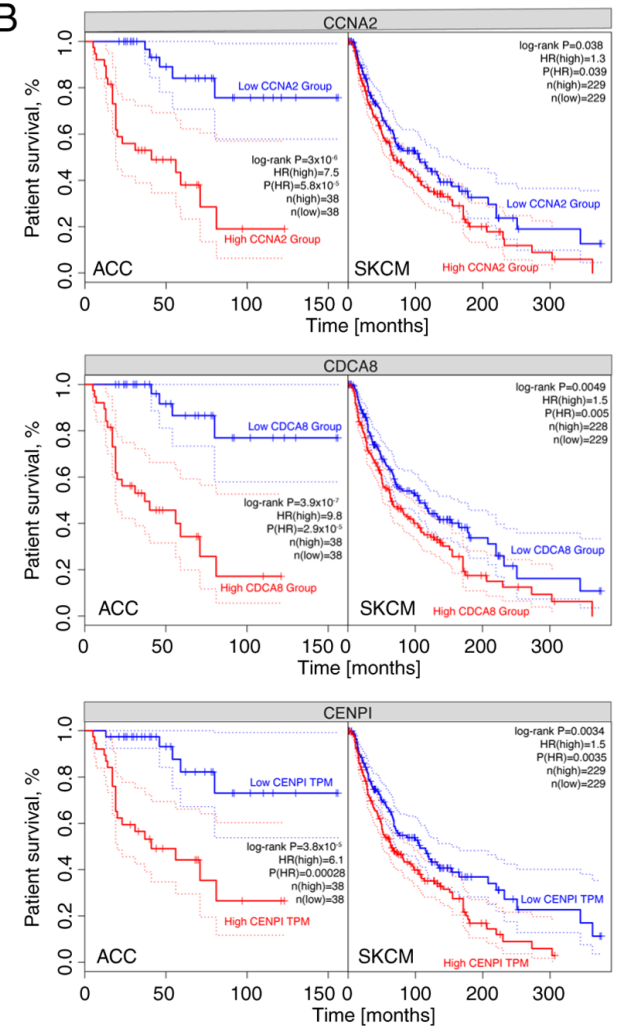
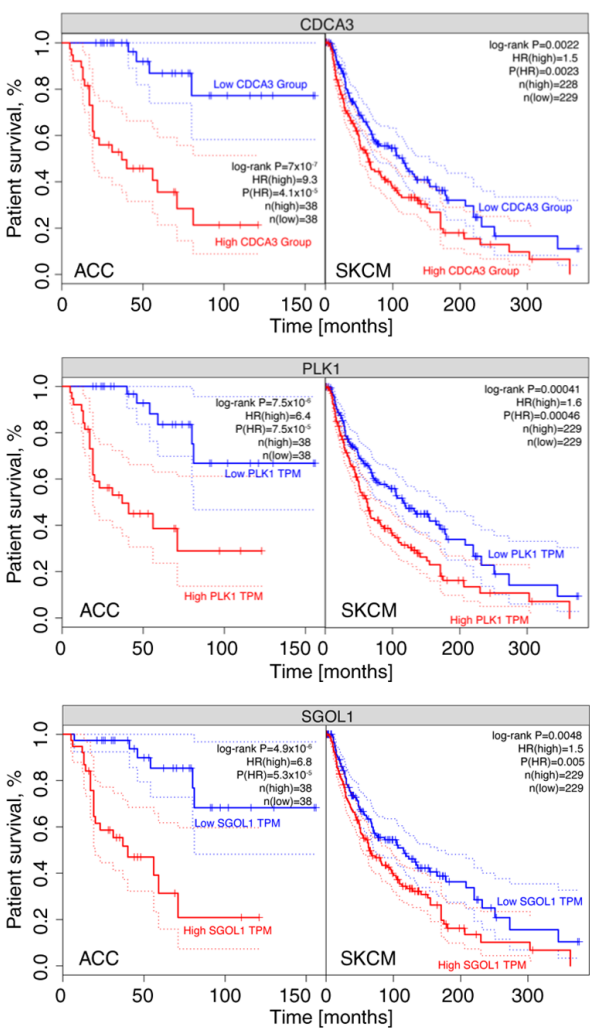

Figure 7. Clinical significance of genes commonly regulated by mitotane in the survival of patients with cancer. (A) Expression results for ACC and from The Cancer Genome Atlas database. The expression level for all analyzed genes was divided into high (above median) and low (below median) expression. Those groups were used to calculate HRs. (B) Genes in which both HRs were statistically significant were subjected to Kaplan-Meier survival analysis. ACC, adrenocortical carcinoma; SKCM, skin cutaneous melanoma; HR, hazard ratio; CCNA2, cyclin A2; CDCA, cell division cycle associated; PLK1, polo like kinase 1; CENPI, centromere protein I; SGO1, shugoshin 1; TPM, transcripts per kilobase million.

carcinoma) and WM266-4 (metastatic melanoma) cell lines, and a primary melanoma cell line derived from the previously described patient (17). The current study had three main aims: i) To evaluate the impact of mitotane on the proliferation rate of the investigated cells; ii) to examine the expression of a wide panel of proteins and genes involved in DDR mechanisms; and iii) to investigate the gene expression profile of the treated cells.

The HAC15 cell line constitutes a suitable model for defining the molecular mechanisms regulating aldosterone and cortisol production, and can be applied to studies on normal adrenal cell function or ACC (50). Furthermore, unlike the commonly used NCI-H295R cell line, the HAC15 cell line responds to stimulation with all major adrenal secretagogues such as angiotensin II, $\mathrm{K}^{+}$and adrenocorticotropic hormone (ACTH), which lead to the stimulation of adrenal hormone biosynthesis (51). Thus, this cell line appears to closely reflect adrenal physiology and is widely used in research. Additionally, the present microarray results confirm the high expression of key adrenal steroidogenesis genes in the HAC15 line, as well as its susceptibility to ACTH and forskolin stimulation (26).

Poli et al (52) cultured NCI-H295R cells in the presence of increasing concentrations of mitotane. Treatment with mitotane reduced cell numbers in a dose- and time-dependent manner, which was attributed to an inhibitory effect on cell viability and proliferation. The data showed that mitotane levels in the therapeutic window $(30-50 \mu \mathrm{M})$ exerted a cytotoxic effect that was associated with the inhibition of cell proliferation. The present study has also demonstrated that mitotane reduces the proliferation rate of both ACC and melanoma cells (Fig. 1). This effect was dose-dependent (10-80 $\mu \mathrm{M})$ and particularly noticeable in primary melanoma cells, where inhibition of proliferation was evident even at low concentrations of mitotane. After changing the medium (in the control group) or administering the drug under investigation, a rapid decrease in impedance is commonly observed, which then stabilizes. Additionally, in the case of WM266-4 cells, the graph shows a smaller range on the $y$-axis, which leads to the formation of a less pronounced proliferation curve at the individual values.

Seidel et al (53) generated a mitotane-resistant HAC15 cell line, and found that resistant clones had the ability to maintain normal mitochondrial and nucleolar morphology during treatment. Resistance was attributed to, among other factors, altered intracellular lipid homeostasis and decreased steroid production (53). This finding is consistent with the present study result showing that mitochondrial integrity plays a crucial role in response to mitotane treatment (Fig. 2A). Bikas et al (54) examined the effect of mitotane on different histological subtypes of thyroid cancer, using the same concentration $(50 \mu \mathrm{M})$ and time point $(24 \mathrm{~h})$ as those used in the present study. The study observed that treatment with mitotane promoted DSBs and activated the apoptotic process, while also reducing the mitochondrial membrane potential. Consistent with these reports, the present study also found that mitotane-treated adrenal cells presented higher levels of histone $\gamma \mathrm{H} 2 \mathrm{AX}$ expression and cleaved PARP-1 based on flow 
cytometry reflecting DSBs and apoptosis (Fig. 2B and 2D) as well as necrosis (Fig. 2C). Cerquetti et al (55) found that mitotane interferes with the modulation of two DNA mismatch repair protein enzymes (DNA mismatch repair protein MSH1 and DNA mismatch repair protein MSH2), which form part of the mismatch DNA repair mechanism, which could explain the radiosensitizing properties of mitotane. In the current study, mitotane treatment promoted the expression of numerous genes involved in DSB repair, including BRCA2, XRCC4 and RAD51. Importantly, those genes were upregulated or downregulated according to the type of cell, indicating that ACC and melanoma cells appear to promote different DNA repair mechanisms at different levels.

It has been reported that combined treatment with mitotane and ionizing radiation (IR) induces accumulation of H295R and SW13 cells in $G_{2}$ phase (56). Mitotane can enhance the cytotoxic effects of IR via the attenuation of DNA repair and interference in the activation of mitosis-promoting factor, which is mainly regulated by cyclin B1 degradation. This phenomenon may explain the defective activation of $\mathrm{CDC} 2$, which is involved in $\mathrm{G}_{2} / \mathrm{M}$ phase arrest, and probably induced by concurrent treatment with mitotane and IR (56). However, the present study found that mitotane administered alone triggered the accumulation of cells (ACC and melanoma) in the $\mathrm{G}_{1}$ phase of the cell cycle (Fig. 2E), leading to a smaller percentage of cells in the $\mathrm{S}$ and $\mathrm{G}_{2}$ phases. This finding was further confirmed by analyzing CDK2 and CDK4 gene expression, since an inverse correlation between CDK2 and CDK4 gene expression was observed, which is logical, considering that each gene is characteristic of a different phase of the cell cycle (namely, CDK2 of the $\mathrm{G}_{2} / \mathrm{M}$ transition and CDK4 of the $\mathrm{G}_{1}$ phase).

Volante et al (57) evaluated the expression of ribonucleotide reductase large subunit 1 (RRM1) in a cohort of patients with ACC, and evaluated the association of gene expression with clinical outcomes, finding that RRM1 gene expression was functionally associated with mitotane sensitivity, thus supporting a potential role for RRM1 determination as a novel molecular biomarker to predict response to adjuvant mitotane in patients with ACC. The present study analyzed the whole transcriptome of treated cells using microarray analysis (Figs. 3-6). The results revealed that primary melanoma, WM266-4 and HAC15 cells had distinct gene expression profiles. The largest changes in gene expression profiles after mitotane administration were observed in HAC15 cells (Fig. 3). Next, it was demonstrated that mitotane triggered changes in BPs involved in DDR; more specifically, it decreased cell division activity with mitotic nuclear division in adrenocortical cells (Fig. 4A and B). Seidel et al (53) found that untreated resistant HAC15 cells showed significant upregulation of genes involved in apoptosis regulation and downregulation of pathways associated with steroid metabolism, regulation of the ERK cascade, apoptotic cell clearance and response to xenobiotics. In that study, mitotane treatment $(70 \mu \mathrm{M})$ of control cells upregulated several pathways, including cell death and unfolded protein response. By contrast, pathways related to lipid homeostasis and transport were downregulated (53). In another study, GSEA of GO categories revealed reduced expression of 36 gene sets $48 \mathrm{~h}$ after mitotane treatment of NCI-H295R cells, reduced expression of 124 gene sets at $72 \mathrm{~h}$ of treatment, overexpression of 1 gene set at $48 \mathrm{~h}$ of treatment and overexpression of 21 gene sets at $72 \mathrm{~h}$ of treatment. Reduced expression of lipid biosynthesis, steroid biosynthesis, steroid metabolic process and several cell cycle categories (such as mitosis and $\mathrm{M}$ phase) were typically observed at 48 and $72 \mathrm{~h}$ post-treatment (58).

By pathway analysis of expression genomics data, Sbiera et al (16) revealed activation of endoplasmic reticulum stress and marked alteration of lipid-related genes caused by mitotane treatment in NCI-H295 cells. To the best of our knowledge, there are no studies on the gene expression profile of different types of cells treated with mitotane. Based on GSEA, the present study obtained similar results to those described by Sbiera et al (16). Mitotane caused ER stress, and reduced the sterol biosynthetic process, mitotic sister chromatid segregation and cell cycle $\mathrm{G}_{2}$ checkpoint, inter alia (Fig. 5). In all the cell types evaluated in the current study, common modifications in BPs were observed, such as activation of cellular amino acid biosynthetic process, and attenuation of cell division (Fig. 6A and B). Several genes, including CCNA2, CDCA3, CDCA8, PLK1, CENP1, SGOL1, KIF18B, KIF20A, anillin actin binding protein and NUF2 component of NDC80 kinetochore complex, are of particular interest, as their expression was attenuated in all cell types after mitotane treatment (Fig. 6C). These genes are all involved in the control of the cell cycle and division.

Regarding cancer survival, the present study focused on the role of the following genes, which are commonly regulated by mitotane: CCNA2, CDCA3, CDCA8, PLK1, CENP1 and SGOL1 (Fig. 7). Expression of these genes below the median levels correlates with higher survival rates in patients diagnosed with ACC and SKCM. The role of these selected genes in cancer prognosis has been reported. Liu et al (59) observed that PLK1 is a potential target for cancer therapy, as it plays multiple roles in the cell cycle, controlling mitotic entry and $\mathrm{G}_{2} / \mathrm{M}$ checkpoint, and coordinates centrosome and cell cycle. In addition, PLK1 also regulates spindle assembly and chromosome segregation, and facilitates DNA replication. Overexpression of this gene is associated with a poor prognosis in patients with cancer. Similarly, KIF18B and KIF20A mediate basic cell physiology through the regulation of the cell cycle, DNA replication, and biological DNA repair processes and pathways. This explains why KIF18B and KIF20A, both of which play an important role in cell cycle regulation, influence clinical outcomes in patients with lung adenocarcinoma (60). Furthermore, overexpression of tumor-related KIFs is correlated with worse outcomes in breast cancer and hepatocellular carcinoma; thus, KIFs may serve as prognostic biomarkers in these cancer types $(61,62)$. The mRNA and protein levels of CENPI are significantly increased in estrogen receptor (ER)-positive breast carcinoma, but not in ER-negative breast carcinoma. Well-established prognostic tests, such as Adjuvant! Online and the Nottingham Prognostic Index, suggest that the overexpression of CENPI is a strong independent marker for a poor prognosis and poor survival in patients with ER-positive breast cancer (63). A previous study showed that CCNA2 was a significant prognostic indicator in ER-positive breast cancer progression and tamoxifen resistance (64). CCNA2 is overexpressed in numerous cancer types, which indicates its potential role in cancer transformation and progression. CCNA2 may also be involved in the processes of epithelial-mesenchymal transition and metastasis (65). Three members of the cell division cycle-associated gene family 
(CDCA3, CDCA5 and CDCA8) are distinctly overexpressed in breast cancer tumors and cell lines. This overexpression is associated with a poor prognosis, with a low survival probability (66). Overall, decreased expression of these genes after mitotane treatment in the present study appears to be a reliable prognostic factor.

In conclusion, the present study aimed to clarify the mechanism by which mitotane, which is routinely used to treat ACC, affects other cell types. The current in vitro findings suggest that mitotane is not as effective in melanoma as in adrenal carcinoma. In the present study, mitotane had the greatest effect on a human ACC cell line, followed by a medium effect on an established metastatic human melanoma cell line. In the cell line derived from metastatic human melanoma, the response to mitotane was moderate. The three cell lines differed in terms of the intensity of their response to mitotane (primary metastatic melanoma cell line $<$ established metastatic melanoma cell line < human adrenal carcinoma cell line), and in their activation of different signaling pathways.

It is important to emphasize that the patient reported in the present study, who exhibited metastatic melanoma in the adrenal glands, responded well to mitotane therapy, and this real-world evidence is superior to the findings derived from in vitro experiments, including those performed in the current study. As a result, it is difficult to clarify the mechanism by which mitotane affects different cell types, and therefore, further studies are required. In conclusion, the present study provides a detailed description of the mechanisms that appear to be activated in response to mitotane treatment.

\section{Acknowledgements}

Not applicable.

\section{Funding}

This research was supported by 'Opus Grant' program of the National Science Center No. UMO-2017/25/B/ /NZ4/00065. Zhanat Komekbai (WKMOMU) \& Agnieszka Malinska (PUMS) were supported by the Social Health Insurance Project, Republic of Kazakhstan (Contract No. SHIP-2.3/CS-02).

\section{Availability of data and materials}

The microarray datasets generated and/or analyzed during the current study are available in the Gene Expression Omnibus repository at the National Center for Biotechnology Information (http://www.ncbi.nlm.nih.gov/geo/) under GEO accession number GSE186870. The remaining datasets used and/or analyzed during the current study are available from the corresponding author on reasonable request.

\section{Authors' contributions}

ES, HK and MR confirm the authenticity of all the raw data. ES was involved in the performing experiments and writing of the original draft; HK participated in conceptualization, methodology, writing, reviewing and editing; KJ performed experiments; AZ validated the data and took part in experiments concerning cell culture and proliferation analysis; DI conducted formal analysis of the data; AM was responsible for bioinformatic data analysis and participated in flow cytometry analyses; BS conducted experiments; ZK bioinformatic data analysis and was engaged in qPCR analysis; MK and TW were responsible for obtaining and handling primary material from the patient as well establishing the primary cell line; WMS validated the data and performed microarray analysis; MRuch was responsible for TCGA data analysis and cell culture; and MRuci participated in project supervision and took part in all experiments. All authors were involved in the preparation and modification of the figures and manuscript. All authors have read and approved the final manuscript.

\section{Ethics approval and consent to participate}

The patient mentioned in the present study provided written informed consent. The current study was approved by the Bioethics Committee of Poznan University of Medical Sciences (Poznan, Poland; approval no. 255/15).

\section{Patient consent for publication}

Not applicable.

\section{Competing interests}

The authors declare that they have no competing interests.

\section{References}

1. Else T, Kim AC, Sabolch A, Raymond VM, Kandathil A, Caoili EM, Jolly S, Miller BS, Giordano TJ and Hammer GD: Adrenocortical carcinoma. Endocr Rev 35: 282-326, 2014.

2. Bertazza L, Barollo S, Mari ME, Faccio I, Zorzan M, Redaelli M, Rubin B, Armanini D, Mian C and Pezzani R: Biological effects of EF24, a curcumin derivative, alone or combined with mitotane in adrenocortical tumor cell lines. Molecules 24: 2202, 2019.

3. Libé R: Adrenocortical carcinoma (ACC): Diagnosis, prognosis, and treatment. Front Cell Dev Biol 3: 45, 2015.

4. Pianovski MAD, Maluf EM, de Carvalho DS, Ribeiro RC, Rodriguez-Galindo C, Boffetta $\mathrm{P}$, Zancanella $\mathrm{P}$ and Figueiredo BC: Mortality rate of adrenocortical tumors in children under 15 years of age in Curitiba, Brazil. Pediatr Blood Cancer 47: 56-60, 2006.

5. Ayala-Ramirez M, Jasim S, Feng L, Ejaz S, Deniz F, Busaidy N, Waguespack SG, Naing A, Sircar K, Wood CG, et al: Adrenocortical carcinoma: Clinical outcomes and prognosis of 330 patients at a tertiary care center. Eur J Endocrinol 169: 891-899, 2013.

6. Boulate G, Amazit L, Naman A, Seck A, Paci A, Lombes A, Pussard E, Baudin E, Lombes M and Hescot S: Potentiation of mitotane action by rosuvastatin: New insights for adrenocortical carcinoma management. Int J Oncol 54: 2149-2156, 2019.

7. Łebek-Szatańska A, Nowak KM and Papierska L: Pitfalls in the diagnostics of aldosterone-producing adre-nocortical carcinoma. Endokrynol Pol 71: 575-576, 2020.

8. Rubin B, Pilon C, Pezzani R, Rebellato A and Fallo F: The effects of mitotane and $1 \alpha, 25$-dihydroxyvitamin $\mathrm{D}_{3}$ on Wnt/beta-catenin signaling in human adrenocortical carcinoma cells. J Endocrinol Invest 43: 357-367, 2020.

9. Cusato J, De Francia S, Allegra S, Carrella S, PirroE, Piccione FM, De Martino F, Ferrero A, Daffara FC, Terzolo M, et al: Circannual variation of mitotane and its metabolites plasma levels in patients with adrenocortical carcinoma. J Pharm Pharmacol 69: 1524-1530, 2017.

10. Liu X, Fu Q, Tang Y, Deng JH, Mei D and Zhang B: A case report of neurological adverse events caused by short-term and low-dose treatment of mi-totane: The role of therapeutic drug monitoring. Medicine (Baltimore) 99: e22620, 2020. 
11. Hescot S, Seck A, Guerin M, Cockenpot F, Huby T, Broutin S, Young J, Paci A, Baudin E and Lombès M: Lipoprotein-free mitotane exerts high cytotoxic activity in adrenocortical carcinoma. J Clin Endocrinol Metab 100: 2890-2898, 2015.

12. Almeida MQ, Bezerra-Neto JE, Mendonça BB, Latronico AC and Fragoso MCBV: Primary malignant tumors of the adrenal glands. Clinics (Sao Paulo) 73 (Suppl 1): e756s, 2018.

13. Frycz BA and Jagodzinski PP: Expression of genes encoding steroidogenic enzymes and their role in prostate carcinogenesis. J Med Sci 83: 73-80, 2014.

14. Paragliola RM, Torino F, Papi G, Locantore P, Pontecorvi A and Corsello SM: Role of mitotane in adrenocortical carcinoma-review and state of the art. Eur Endocrinol 14: 62-66, 2018.

15. Hescot S, Amazit L, Lhomme M, Travers S, DuBow A, Battini S, Boulate G, Namer IJ, Lombes A, Kontush A, et al: Identifying mitotane-induced mitochondria-associated membranes dysfunctions: Metabolomic and lipidomic approaches. Oncotarget 8: 109924-109940, 2017.

16. Sbiera S, Leich E, Liebisch G, Sbiera I, Schirbel A, Wiemer L, Matysik S, Eckhardt C, Gardill F, Gehl A, et al: Mitotane inhibits sterol-O-acyl transferase 1 triggering lipid-mediated endoplasmic reticulum stress and apoptosis in adrenocortical carcinoma cells. Endocrinology 156: 3895-3908, 2015.

17. Komarowska H, Bromińska B, Janicka-Jedyńska $M$ and Ruchała M: Adrenal incidentaloma: Nothing is ever as it seems. Am J Med 133: 1048-1050, 2020.

18. Luo X, Mitra D, Sullivan RJ, Wittner BS, Kimura AM, Pan S, Hoang MP, Brannigan BW, Lawrence DP, Flaherty KT, et al: Isolation and molecular characterization of circulating melanoma cells. Cell Rep 7: 645-653, 2014.

19. Weinstein D, Leininger J, Hamby C and Safai B: Diagnostic and prognostic biomarkers in melanoma. J Clin Aesthet Dermatol 7: 13-24, 2014.

20. Wassermann JD, Novokmet A, Eichler-Jonsson C, Ribeiro RC, Rodriguez-Galindo C, Zambetti GP and Malkin D: Prevalence and functional consequence of P53 mutations in pediatric adrenocortical carcinoma: A children's oncology group study. J Clin Oncol 33: 602-609, 2015.

21. Ji Z, Njauw CN, Taylor M, Neel V, Flaherty KT and Tsao H: P53 rescue through HDM2 antagonism suppresses melanoma growth and potentiates MEK inhibition. J Invest Dermatol 132: 356-364, 2012.

22. Lehmann TP, Wrzesiński T and Jagodziński PP: The effect of mitotane on viability, steroidogenesis and gene expression in NCI-H295R adrenocortical cells. Mol Med Rep 7: 893-900, 2013

23. Dworakowska D, Drabarek A, Wenzel I, Babińska A Świątkowska-Stodulska R and Sworczak K: Adrenocortical cancer (ACC)-literature overview and own experience. Endokrynol Pol 65: 492-502, 2014

24. Sivandzade F, Bhalerao A and Cucullo L: Analysis of the mitochondrial membrane potential using the cationic JC-1 dyeas a sensitive fluorescent probe. Bio Protoc 9: e3128, 2019.

25. Livak KJ and Schmittgen TD: Analysis of relative gene expression data using real-time quantitative PCR and the 2(-Delta Delta C(T)) method. Methods 25: 402-408, 2001.

26. Stelcer E, Milecka P, Komarowska H, Jopek K, Tyczewska M, Szyszka M, Lesniczak M, Suchorska W, Bekova K Szczepaniak B, et al: Adropin stimulates proliferation and inhibits adrenocortial steroidogenesis in the human adrenal carcinoma (HAC15) cell line. Front Endocrinol (Lausanne) 11: 561370, 2020.

27. Szyszka M, Paschke L, Tyczewska M, Jopek K, Celichowski P, Milecka P, Sultanova G, Stelcer E, Malinska A, Malendowicz LK and Rucinski M: Analysis of transcriptome, selected intracellular signaling pathways, proliferation and apoptosis of LNCaP cells exposed to high leptin concentrations. Int J Mol Sci 20: 5412 , 2019.

28. Jopek K, Celichowski P, Szyszka M, Tyczewska M, Milecka P, Malendowicz LK and Rucinski M: Transcriptome profile of rat adrenal evoked by gonadectomy and testosterone or estradiol replacement. Front Endocrinol (Lausanne) 8: 26, 2017.

29. Gautier L, Cope L, Bolstad BM and Irizarry RA: Affy-analysis of affymetrix genechip data at the probe level. Bioinformatics 20 : 307-315, 2004

30. Carvalho BS and Irizarry RA: A framework for oligonucleotide microarray preprocessing. Bioinformatics 26: 2363-2367, 2010.

31. Ritchie ME, Phipson B, Wu D, Hu Y, Law CW, Shi W and Smyth GK: Limma powers differential expression analyses for RNA-sequencing and microarray studies. Nucleic Acids Res 43: e47, 2015 .
32. Dennis G Jr, Sherman BT, Hosack DA, Yang J, Gao W, Lane HC and Lempicki RA: DAVID: Database for annotation, visualization, and integrated discovery. Genome Biol 4: P3, 2003.

33. Fresno $\mathrm{C}$ and Fernández EA: RDAVIDWebService: $A$ versatile $\mathrm{R}$ interface to DAVID. Bioinformatics 29: 2810-2811, 2013.

34. Benjamini Y and Cohen R: Weighted false discovery rate controlling procedures for clinical trials. Biostatistics 18: 91-104, 2017.

35. Walter W, Sánchez-Cabo F and Ricote M: GOplot: An R package for visually combining expression data with functional analysis. Bioinformatics 31: 2912-2914, 2015.

36. Damian D and Gorfine M: Statistical concerns about the GSEA procedure. Nat Genet 36: 663, 2004

37. Sergushichev AA: An algorithm for fast preranked gene set enrichment analysis using cumulative statistic calculation. bioRxiv: Jun 20,2016 (Epub ahead of print).

38. Liberzon A, Birger C, Thorvaldsdóttir H, Ghandi M, Mesirov JP and Tamayo P: The molecular signatures database (MSigDB) hallmark gene set collection. Cell Syst 1: 417-425, 2015

39. Subramanian A, Tamayo P, Mootha VK, Mukherjee S, Ebert BL, Gillette MA, Paulovich A, Pomeroy SL, Golub TR, Lander ES and Mesirov JP: Gene set enrichment analysis: A knowledge-based approach for interpreting genome-wide expression profiles. Proc Natl Acad Sci USA 102: 15545-15550, 2005.

40. Isserlin R, Merico D, Voisin V and Bader GD: Enrichment map-a Cytoscape app to visualize and explore OMICs pathway enrichment results. F1000Res 3: 141, 2014.

41. Kucera M, Isserlin R, Arkhangorodsky A and Bader GD AutoAnnotate: A Cytoscape app for summarizing networks with semantic annotations. F1000Res 5: 1717, 2016.

42. Kolde R: J.R.p.v: Pheatmap: Pretty Heatmaps. p617, 2012

43. Deng M, Brägelmann J, Kryukov I, Saraiva-Agostinho N and Perner S: FirebrowseR: An R client to the broad institute's Firehose Pipeline. Database (Oxford) 2017: baw160, 2017.

44. Tang Z, Kang B, Li C, Chen T and Zhang Z: GEPIA2: An enhanced web server for large-scale expression profiling and interactive analysis. Nucleic Acids Res 47: W556-W560, 2019.

45. Eaton A, Therneau T and Le-Rademacher J: Designing clinical trials with (restricted) mean survival time endpoint: Practical considerations. Clin Trials 17: 285-294, 2020.

46. Hu B, Mitra J, van den Heuvel S and Enders GH: S and G2 phase roles for Cdk2 revealed by inducible expression of a dominant-negative mutant in human cells. Mol Cell Biol 21: 2755-2766, 2001.

47. Zhang X, Dong W, Zhou H, Li H, Wang N, Miao X and Jia L: $\alpha-2,8$-Sialyltransferase is involved in the development of multidrug resistance via PI3K/Akt pathway in human chronic myeloid leukemia. IUBMB Life 67: 77-87, 2015.

48. Fujita Y, Ito M and Ohsawa I: Mitochondrial stress and GDF15 in the pathophysiology of sepsis. Arch Biochem Biophys 696: $108668,2020$.

49. Li T, Su L, Lei Y, Liu X, Zhang Y and Liu X: DDIT3 and KAT2A proteins regulate TNFRSF10A and TNFRSF10B expression in endoplasmic reticulum stress-mediated apoptosis in human lung cancer cells. J Biol Chem 290: 11108-11118, 2015.

50. Parmar J, Key RE and Rainey WE: Development of an Adrenocorticotropin-responsive human adrenocortical carcinoma cell line. J Clin Endocrinol Metab 93: 4542-4546, 2008.

51. Wang T and Rainey WE: Human adrenocortical cell lines. Mol Cell Endocrinol 351: 58-65, 2012.

52. Poli G, Guasti D, Rapizzi E, Fucci R, Canu L, Bandini A, Cini N, Bani D, Mannelli M and Luconi M: Morphofunctional effects of mitotane on mitochondria in human adrenocortical cancer cells. Endocr Relat Cancer 20: 537-550, 2013.

53. SeidelE, Walenda G, Messerschmidt C, Obermayer B, Peitzsch M, Wallace P, Bahethi R, Yoo T, Choi M, Schrade P, et al: Generation and characterization of a mitotane-resistant adrenocortical cell line. Endocr Connect 9: 122-134, 2020.

54. Bikas A, Jensen K, Patel A, Costello J, Kaltsas G, Hoperia V, Wartofsky L, Burman K and Vasko V: Mitotane induces mitochondrial membrane depolarization and apoptosis in thyroid cancer cells. Int J Oncol 55: 7-20, 2019.

55. Cerquetti L, Sampaoli C, Amendola D, Bucci B, Misiti S, Raza G, De Paula U, Marchese R, Brunetti E, Toscano V and Stigliano A: Mitotane sensitizes adrenocortical cancer cells to ionizing radiations by involvement of the cyclin B1/CDK complex in G2 arrest and mismatch repair enzymes modulation. Int J Oncol 37: 493-501, 2010.

56. Cerquetti L, Bucci B, Carpinelli G, Lardo P, Proietti A, Saporito R, Rindi G, Petrangeli E, Toscano V and Stigliano A: Antineoplastic effect of a combined mitotane treatment/ionizing radiation in adrenocortical carcinoma: A preclinical study. Cancers (Basel) 11: 1768, 2019. 
57. Volante M, Terzolo M, Fassnacht M, Rapa I, Germano A Sbiera S, Daffara F, Sperone P, Scagliotti G, Allolio B, et al: Ribonucleotide reductase large subunit (RRM1) gene expression may predict efficacy of ad-juvant mitotane in adrenocortical cancer. Clin Cancer Res 18: 3452-3461, 2012.

58. Zsippai A, Szabó DR, Tömböl Z, Szabó PM, Eder K, Pállinger E, Gaillard RC, Patócs A, Tóth S, Falus A, et al: Effects of mitotane on gene expression in the adrenocortical cell line NCI-H295R: A microarray study. Pharmacogenomics 13: 1351-1361, 2012.

59. Liu Z, Sun Q and Wang X: PLK1, a potential target for cancer therapy. Transl Oncol 10: 22-32, 2017.

60. Zhang L, Zhu G, Wang X, Liao X, Huang R, Huang C, Huang P, Zhang $\mathrm{J}$ and Wang P: Genomewide investigation of the clinical significance and prospective molecular mechanisms of kinesin family member genes in patients with lung adenocarcinoma. Oncol Rep 42: 1017-1034, 2019.

61. Li TF, Zeng HJ, Shan Z, Ye RY, Cheang TY, Zhang YJ, Lu SH, Zhang Q, Shao N and Lin Y: Overexpression of kinesin superfamily members as prognostic biomarkers of breast cancer. Cancer Cell Int 20: 123, 2020.
62. Li X, Huang W, Huang W, Wei T, Zhu W, Chen G and Zhang J: Kinesin family members KIF2C/4A/10/11/14/18B/20A/23 predict poor prognosis and promote cell proliferation in hepatocellular carcinoma. Am J Transl Res 12: 1614-1639, 2020.

63. Thangavelu PU,Lin CY, Vaidyanathan S, Nguyen THM, Dray E and Duijf PHG: Overexpression of the E2F target gene CENPI promotes chromosome instability and predicts poor prognosis in estrogen receptor-positive breast cancer. Oncotarget 8: 62167-62182, 2017.

64. Gao T, Han Y, Yu L, Ao S, Li Z and Ji J: CCNA2 is a prognostic biomarker for ER+ breast cancer and tamoxifen resistance. PLoS One 9: e91771, 2014.

65. Bendris N, Arsic N, Lemmers B and Blanchard JM: Cyclin A2, Rho GTPases and EMT. Small GTPases 3: 225-228, 2012.

66. Phan NN, Wang CY, Li KL, Chen CF, Chiao CC, Yu HG, Huang PL and Lin YC: Distinct expression of CDCA3, CDCA5, and CDCA8 leads to shorter relapse free survival in breast cancer patient. Oncotarget 9: 6977-6992, 2018.

This work is licensed under a Creative Commons Attribution-NonCommercial-NoDerivatives 4.0 International (CC BY-NC-ND 4.0) License. 